\title{
Dibismuthates as Linking Units for Bis-Zwitterions and Coordination Polymers
}

\author{
Csilla Fekete, Jamie Barrett, Zoltán Benko,* and Dominikus Heift* \\ Cite This: Inorg. Chem. 2020, 59, 13270-13280 \\ Read Online
}

ABSTRACT: Adducts of bismuth trihalides $\mathrm{BiX}_{3}(\mathrm{X}=\mathrm{Cl}, \mathrm{Br}, \mathrm{I})$ and the $\mathbf{P S}_{3}$ ligand $\left(\mathbf{P S}_{3}=\mathrm{P}\left(\mathrm{C}_{6} \mathrm{H}_{4}-\mathrm{o}-\mathrm{CH}_{2} \mathrm{SCH}_{3}\right)_{3}\right)$ react with $\mathrm{HCl}$ to form inorganic/organic hybrids with the general formula $\left[\mathrm{HPS}_{3} \mathrm{BiX}_{4}\right]_{2}$. On the basis of their solid-state structures determined by single-crystal X-ray diffraction, these compounds exhibit discrete bis-zwitterionic assemblies consisting of two phosphonium units $\left[\mathrm{HPS}_{3}\right]^{+}$linked to a central dibismuthate core $\left[\mathrm{Bi}_{2} \mathrm{X}_{8}\right]^{2-}$ via $\mathrm{S} \rightarrow \mathrm{Bi}$ dative interactions. Remarkably, the phosphorus center of the $\mathbf{P S}_{3}$ ligand undergoes protonation with hydrochloric acid. This is in stark contrast to the protonation of phosphines commonly observed with hydrogen halides resulting in equilibrium. To understand the important factors in this protonation

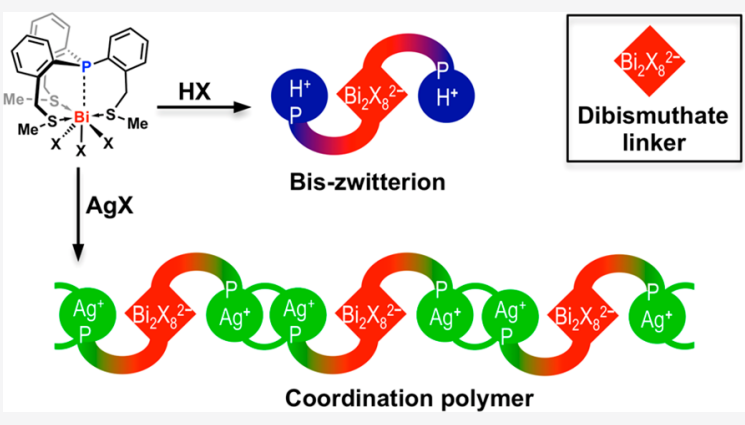
reaction, ${ }^{31} \mathrm{P}$ NMR experiments and DFT computations have been performed. Furthermore, the dibismuthate linker was utilized to obtain the coordination polymer $\left\{\left[\mathrm{AgPS}_{3} \mathrm{BiCl}_{3}(\mathrm{OTf})\right]_{2}\left(\mathrm{CH}_{3} \mathrm{CN}\right)_{2}\right\}_{\infty}$, in which dicationic $\left[\mathrm{Ag}\left(\mathbf{P S}_{3}\right)\right]_{2}{ }^{2+}$ macrocycles containing five-coordinate silver centers connect the dianionic $\left[\mathrm{Bi}_{2} \mathrm{Cl}_{6}(\mathrm{OTf})_{2}\right]^{2-}$ dibismuthate fragments. The bonding situation in these dibismuthates has been investigated by single-crystal X-ray diffraction and DFT calculations (NBO analysis, AIM analysis, charge distribution).

\section{INTRODUCTION}

Halobismuthate(III) anions have been known for over 100 years. For example, dissolving bismuth trichloride in hydrochloric acid leads to the formation of the $\left[\mathrm{BiCl}_{4}\right]^{-}$monoanion and the $\left[\mathrm{BiCl}_{5}\right]^{2-}$ dianion. ${ }^{1,2}$ Following these simple anions, a plethora of more complex oligomeric and polymeric halobismuthate anions of the general formula $\left[\mathrm{Bi}_{n} \mathrm{X}_{m}\right]^{3 n-m}$ have been discovered. ${ }^{3-5}$ Due to the weakness of the bismuth-halogen bond, these complexes can undergo various association and dissociation processes in solution; however, in the solid state, the versatility of coordination modes around the bismuth center results in a high structural diversity. For example, halobismuthates can be discrete anions with varying nuclearity (zero dimension, OD) or they can form onedimensional (1D) polymeric chains, two-dimensional (2D) networks, or even three-dimensional (3D) architectures. ${ }^{5-18}$ Since the solid-state structure of inorganic/organic hybrids is crucial for applications and depends on several factors, such as the counterion, solvent, temperature, etc., the controlled design of these materials with bespoke properties is difficult, stimulating intense ongoing research in this field.

A common prototype of discrete anions are binuclear dibismuthates of the general formula $\left[\mathrm{Bi}_{2} \mathrm{X}_{m}\right]^{6-m}$, where $m$ can range from 8 to $11 .{ }^{3,4}$ Among these, the rarest species known are for $\left[\mathrm{Bi}_{2} \mathrm{X}_{8}\right]^{2-}$, whose centrosymmetric geometry exhibits two edge-sharing square pyramids and a stereochemically active lone pair at each of the bismuth centers (see Figure $1) .{ }^{19-22}$ In contrast, in the other three anions $(m=9,10$, or<smiles>[X][Si]([X])([X])[X][Si]([X])([X])[X]</smiles>

$\left[\mathrm{Bi}_{2} \mathrm{X}_{8}\right]^{2-}$<smiles>[X][Si]([X])([X])[Z][Si]([X])([X])I</smiles>

$\left[\mathrm{Bi}_{2} \mathrm{X}_{8} \mathrm{~L}_{2}\right]^{2-}$<smiles>[X][Z]([X])([X])[X][Si]([X])([X])[X]</smiles>

$\left[\mathrm{Bi}_{2} \mathrm{X}_{10}\right]^{4-}$<smiles>[X][Si]([X])([X])[Te][R]([X])([X])([X])([X])I</smiles>

$\left[\mathrm{Bi}_{2} \mathrm{X}_{6} \mathrm{Y}_{2} \mathrm{~L}_{2}\right]^{2-}$
Figure 1. Structural diversity of binuclear bismuthate anions $(\mathrm{X}=\mathrm{Cl}$, $\mathrm{Br}, \mathrm{I}$; L = Lewis bases with $\mathrm{O}, \mathrm{N}$, or S donor atoms; $\mathrm{Y}=$ triflate etc.; for details see the text). Except for the $\left[\mathrm{Bi}_{2} \mathrm{X}_{8}\right]^{2-}$ anion the lone pairs at the bismuth centers are not shown, as they typically appear to be stereochemically inactive.

Received: June 2, 2020

Published: September 8, 2020

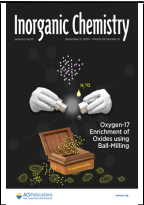


11) the bismuth resides in an octahedral coordination environment. Similar to the $\left[\mathrm{Bi}_{2} \mathrm{X}_{8}\right]^{2-}$ anion, in the dibismuthate $\left[\mathrm{Bi}_{2} \mathrm{X}_{10}\right]^{4-}$ the two hexacoordinated bismuth centers are connected by two $\mu_{2}$-bridging halide ions, and the bridging $\mathrm{Bi}-\mathrm{X}$ distances are longer than the terminal distances. Formally, the $\left[\mathrm{Bi}_{2} \mathrm{X}_{10}\right]^{4-}$ unit can be derived from the $\left[\mathrm{Bi}_{2} \mathrm{X}_{8}\right]^{2-}$ anion by coordinating two further $\mathrm{X}^{-}$anions to the axial positions (occupied by lone pairs in $\left[\mathrm{Bi}_{2} \mathrm{X}_{8}\right]^{2-}$ ). Alternatively, other Lewis bases may play the role of electronpair donors instead of these two halide ions; however, these $\left[\mathrm{Bi}_{2} \mathrm{X}_{8} \mathrm{~L}_{2}\right]^{2-}$ species are less common than the all-halide dibismuthates $\left[\mathrm{Bi}_{2} \mathrm{X}_{10}\right]^{4-}$. The lion's share of the $\left[\mathrm{Bi}_{2} \mathrm{X}_{8} \mathrm{~L}_{2}\right]^{2-}$ structures has been reported with solvent molecules (e.g., $\mathrm{L}=$ $\mathrm{THF}^{20,23-26} \mathrm{H}_{2} \mathrm{O},{ }^{27}$ DMSO, ${ }^{26,28-32}$ acetone ${ }^{28,33,34}$ ) coordinating to the bismuth centers (see Figure 1), but in some cases more sophisticated donor molecules such as bipyridines ${ }^{35-42}$ can act as Lewis bases. On the basis of our CCDC search, the most common donor atom is oxygen, ${ }^{20,23-34,38,42-44}$ followed by nitrogen, ${ }^{35-37,39-41}$ and to our knowledge there is only one example with sulfur (dimethyl sulfide ${ }^{45}$ ).

Furthermore, binuclear bismuthate anions offer the possibility of further functionalization. To our knowledge, there is only one example in which the bridging halides of $\left[\mathrm{Bi}_{2} \mathrm{X}_{8} \mathrm{~L}_{2}\right]^{2-}$ species have formally been replaced by another monoanion, resulting in a $\left[\mathrm{Bi}_{2} \mathrm{X}_{6} \mathrm{Y}_{2} \mathrm{~L}_{2}\right]^{2-}$ type dibismuthate. ${ }^{46}$ More commonly, the terminal halides can also be substituted by other anions (e.g., $\mathrm{X}=$ carboxylate, $\mathrm{Y}=$ nitrate $^{47} \mathrm{X}=\mathrm{Y}=$ thiolates $\left.{ }^{48,49}\right)$. Furthermore, the bridged $\left[\mathrm{Bi}_{2} \mathrm{X}_{2}\right]$ four-membered ring motif is also known in neutral dimers.

Here we report the reactivity of bismuth trihalide complexes with the formula $\mathbf{P S}_{3} \mathrm{BiX}_{3}\left(\mathbf{P S}_{3}=\mathrm{P}\left(\mathrm{C}_{6} \mathrm{H}_{4}-\mathrm{o}-\mathrm{CH}_{2} \mathrm{SCH}_{3}\right)_{3} ; \mathrm{X}=\right.$ $\mathrm{Cl}, \mathrm{Br}, \mathrm{I})$ and hydrochloric acid or silver triflate, delivering dimeric or polymeric dibismuthates of the type $\left[\mathrm{Bi}_{2} \mathrm{X}_{8} \mathrm{~L}_{2}\right]^{2-}$ or $\left[\mathrm{Bi}_{2} \mathrm{X}_{6} \mathrm{Y}_{2} \mathrm{~L}_{2}\right]^{2-}$, respectively. In the starting materials $\mathbf{P S}_{3} \mathrm{BiX}_{3}$ of these reactions the bismuth center is stabilized by the cooperation of three dative $\mathrm{S} \rightarrow \mathrm{Bi}$ bonds and a further $\mathrm{P} \cdots \mathrm{Bi}$ pnictogen interaction, which altogether endow these complexes with significant stabilization energies of $25.9-28.3 \mathrm{kcal} /$ mol. $^{56}$ In this paper we also aim to shed light on the energy requirements for the breakdown of these stabilizing interactions, leading to the formation of dibismuthate units.

\section{RESULTS AND DISCUSSION}

Synthesis and Characterization. When the adduct of the $\mathrm{P}\left(\mathrm{C}_{6} \mathrm{H}_{4}-\mathrm{o}-\mathrm{CH}_{2} \mathrm{SCH}_{3}\right)_{3} \quad\left(\mathbf{P S}_{3}\right)$ ligand and bismuth trichloride $\left(\mathrm{BiCl}_{3}\right)$ (in the following abbreviated as $\mathbf{P S}_{3} \mathrm{BiCl}_{3}$ ) dissolved in dichloromethane was reacted with an excess of $\mathrm{HCl}(4 \mathrm{M}, 1,4-$ dioxane solution), an immediate color change of the solution from yellow to colorless was observed and a colorless, microcrystalline solid of the composition $\left[\mathrm{HPS}_{3} \mathrm{BiCl}_{4}\right]_{2}(\mathbf{1 A}$, Scheme 1) was isolated in a good yield of $91 \%$ (for a singlecrystal X-ray diffraction study see below). This inorganic/ organic hybrid material was analyzed by multinuclear NMR spectroscopy, and the ${ }^{31} \mathrm{P}\left\{{ }^{1} \mathrm{H}\right\}$ NMR spectrum in $\mathrm{CD}_{2} \mathrm{Cl}_{2}$ exclusively shows a singlet resonance at $-20.8 \mathrm{ppm}$, which is significantly different from that of $\mathrm{PS}_{3} \mathrm{BiCl}_{3}$ (-37.0 ppm in $\left.\mathrm{C}_{6} \mathrm{D}_{6}{ }^{56}\right)$ or the free ligand $\mathbf{P S}_{3}\left(-36.9 \mathrm{ppm}\right.$ in $\mathrm{C}_{6} \mathrm{D}_{6},{ }^{56}-36.2$ ppm in $\left.\mathrm{CD}_{2} \mathrm{Cl}_{2}\right)$, indicating a change in the chemical environment of the phosphorus center. In the proton-coupled ${ }^{31} \mathrm{P}$ NMR spectrum this resonance appears as a doublet with a remarkably large ${ }^{1} J\left({ }^{31} \mathrm{P}-{ }^{1} \mathrm{H}\right)$ coupling constant of $535 \mathrm{~Hz}$. The downfield shift of the resonance in comparison to the free ligand, together with the magnitude of the coupling constant, is
Scheme 1. Reaction of $\mathrm{PS}_{3} \mathrm{BiX}_{3}(\mathrm{X}=\mathrm{Cl}, \mathrm{Br}, \mathrm{I})$ with Hydrochloric Acid, Delivering the Inorganic/Organic BisZwitterions $1 \mathrm{~A}-\mathrm{C}$

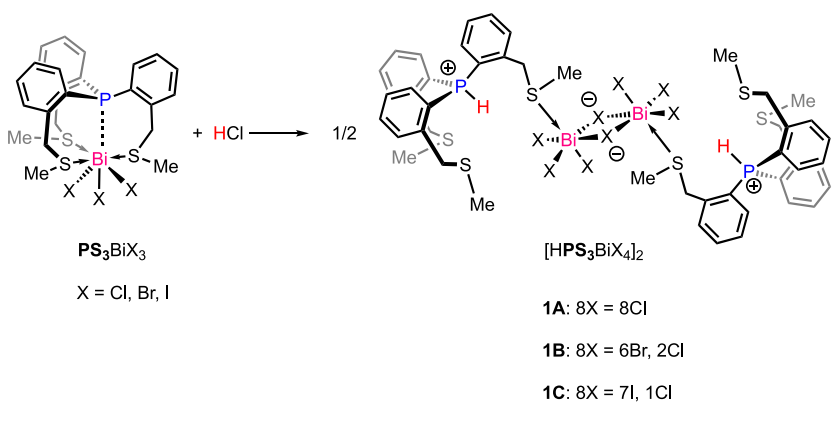

in line with the formation of a phosphonium cation (see ${ }^{1} J\left({ }^{31} \mathrm{P}-{ }^{1} \mathrm{H}\right)=531 \mathrm{~Hz}$ for the triphenylphosphonium cation ${ }^{57}$ or ${ }^{1} J\left({ }^{31} \mathrm{P}-{ }^{1} \mathrm{H}\right)=535 \mathrm{~Hz}$ for $\left.\left[\mathrm{HPS}_{3}\right][\mathrm{OTf}]^{58}\right)$.

Analogously, the reaction was preformed with the heavier analogues $\mathbf{P S}_{3} \mathrm{BiBr}_{3}$ and $\mathbf{P S}_{3} \mathrm{BiI}_{3}$. Again, the ${ }^{31} \mathrm{P} \mathrm{NMR}$ spectrum shows the formation of the phosphonium salts $\mathbf{1 B}$ and $\mathbf{1 C}(\delta$ $-20.7,{ }^{1} J\left({ }^{31} \mathrm{P}-{ }^{1} \mathrm{H}\right)=535 \mathrm{~Hz}$ and $\delta-21.8 \mathrm{ppm},{ }^{1} J\left({ }^{31} \mathrm{P}-{ }^{1} \mathrm{H}\right)=$ $535 \mathrm{~Hz}$, respectively). While the composition of the isolated 1B can be described with six bromide and two chloride anions, the iodine content of $\mathbf{1 C}$ is most likely somewhat larger than expected from the stoichiometry (for details see below and the Supporting Information). Presumably an exchange reaction of the halide substituents around the bismuth center takes place in solution, resulting in a significantly lower yield of 1C (44\%) in comparison to that of $\mathbf{1 A}$ or $\mathbf{1 B}$.

To utilize the sulfur donor functionalities of the $\mathbf{P S}_{3}$ ligand, we decided to test the reactivity of $\mathrm{PS}_{3} \mathrm{BiCl}_{3}$ toward a soft transition-metal center such as $\mathrm{Ag}^{+}$. Therefore, the adduct $\mathrm{PS}_{3} \mathrm{BiCl}_{3}$ was reacted with 1 equiv of silver trifluoromethanesulfonate $(\mathrm{Ag}(\mathrm{OTf}))$ in dry acetonitrile (Scheme 2$)$. The ${ }^{31} \mathrm{P}$

Scheme 2. Reaction of $\mathrm{PS}_{3} \mathrm{BiCl}_{3}$ with Silver Triflate, Delivering Compound $2^{a}$

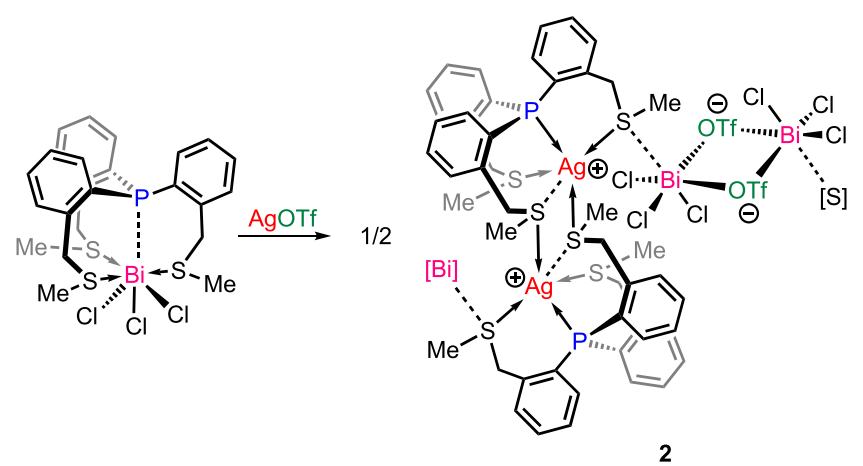

${ }^{a}[\mathrm{Bi}]$ and $[\mathrm{S}]$ denote the continuation of the polymeric chain.

NMR spectrum of the reaction mixture shows a broad singlet resonance at $-33.1 \mathrm{ppm}$ (without observable phosphorussilver coupling) shifted downfield in comparison to the free ligand $\operatorname{PS}_{3}\left(\delta\left({ }^{31} \mathrm{P}\right)-38.0 \mathrm{ppm}\right.$ in acetonitrile), indicating again a change in the chemical environment of the phosphorus center. Even though the coordination chemical shift change of $\Delta \delta\left({ }^{31} \mathrm{P}\right)=\delta($ complex $)-\delta($ ligand $)=+3.8 \mathrm{ppm}$ is smaller than that for triphenylphosphine complexes $\left[\left(\mathrm{PPh}_{3}\right)_{n} \mathrm{Ag}(\mathrm{OTf})\right]$ $\left(\Delta \delta\left({ }^{31} \mathrm{P}\right)=13.6-22.1 \mathrm{ppm}\right.$ for $\left.n=1-4^{59,60}\right)$, together with the broadening of the resonance this is consistent with an 
interaction of the phosphorus and the silver centers. Similar behavior is widely known for silver complexes with neutral ligands and is attributed to the fluxionality of the species in solution. According to a single-crystal X-ray diffraction analysis, in the solid state this material can be described with the formula $\left\{\left[\mathrm{AgPS}_{3} \mathrm{BiCl}_{3} \text { (OTf) }\right]_{2}\left(\mathrm{CH}_{3} \mathrm{CN}\right)_{2}\right\}_{\infty}$ (see below).

Optical Properties of Bis-Zwitterions 1A-C. As isolated solids, compounds $\mathbf{1 A}$ and $\mathbf{1 B}$ are white and yellowish white, respectively; however, $\mathbf{1 C}$ is intense bright red and shows no photoluminescence in the solid state or in solution. In dichloromethane solution, all of these compounds exhibit broad absorption bands (see Figure 2), similarly to other

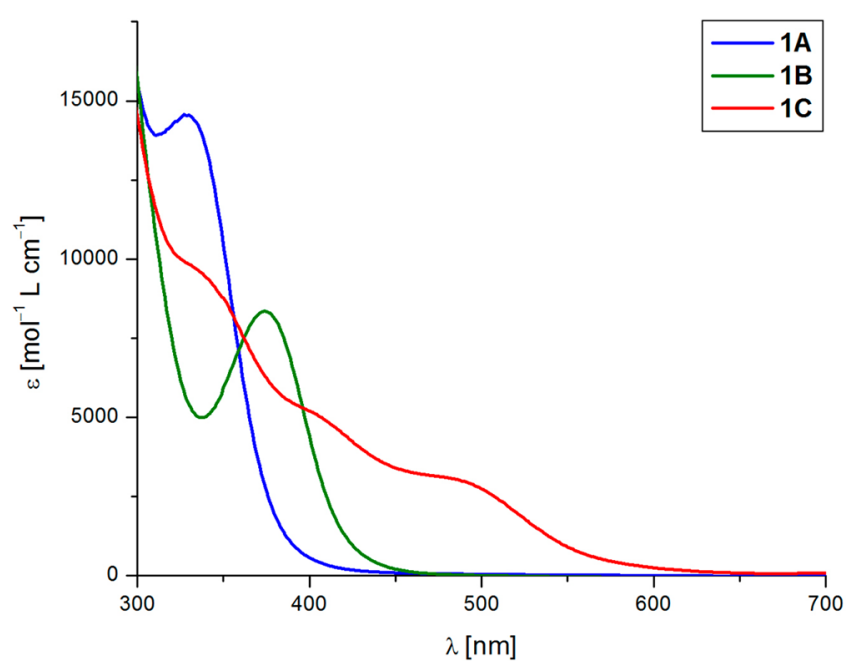

Figure 2. UV-vis spectra of compounds $\mathbf{1 A}-\mathrm{C}$ in dichloromethane $\left(c=10^{-6} \mathrm{~mol} / \mathrm{L}\right)$.

bismuth complexes, ${ }^{42}$ and a clear red shift can be observed in the direction $1 \mathrm{~A} \rightarrow \mathbf{1 B} \rightarrow \mathbf{1 C}\left(\lambda_{\max }=328,374\right.$, and $485 \mathrm{~nm}$, respectively, for the lowest energy excitations). This tendency can be reproduced by time-dependent density functional theory calculations at the TD-B3LYP/def2-SVP level, which predict several closely lying transitions, matching the experimentally observed broad absorption bands. The calculated absorption bands are somewhat shifted toward lower wavelengths (297-330 nm (1A), 303-340 nm (1B), and $376-439 \mathrm{~nm}(\mathbf{1 C}))$ in comparison to the experimental bands; nevertheless, the trend is properly described.

These low-energy excitations typically involve transitions from the dibismuthate core to the $\pi^{*}$ system localized at the two phosphonium units. As an example, the HOMO and LUMO Kohn-Sham orbitals of $\mathbf{1 A}$ are presented in Figure 3 (the LUMO+1, LUMO, HOMO, and HOMO-1 orbitals with their energies are collected in the Table S3 in the Supporting Information). The HOMO of $\mathbf{1 A}$ is formed from the p-type lone pairs located at the halogen centers and the sulfur donor atoms of $\mathbf{P S}_{3}$ with an antibonding combination of the bismuth $\mathrm{s}$ orbital, similarly to those reported for $\left[\mathrm{BiX}_{6}\right]^{3-}(\mathrm{X}=\mathrm{Cl}, \mathrm{I}){ }^{61}$ In contrast, the LUMO is localized at the two phosphonium units and shows $\pi$ symmetry. The red shift observed in the direction of $1 \mathrm{~A}, \mathbf{1 B}$, and $1 \mathrm{C}$ can be explained on the basis of the HOMO-LUMO energies as follows. The LOMO energy of the $\pi^{*}$ system located at the phosphonium units stays practically unchanged in these three compounds; however, the energy of the HOMO orbitals depends on the halogen substituent. As the orbital energies of the lone pairs at the
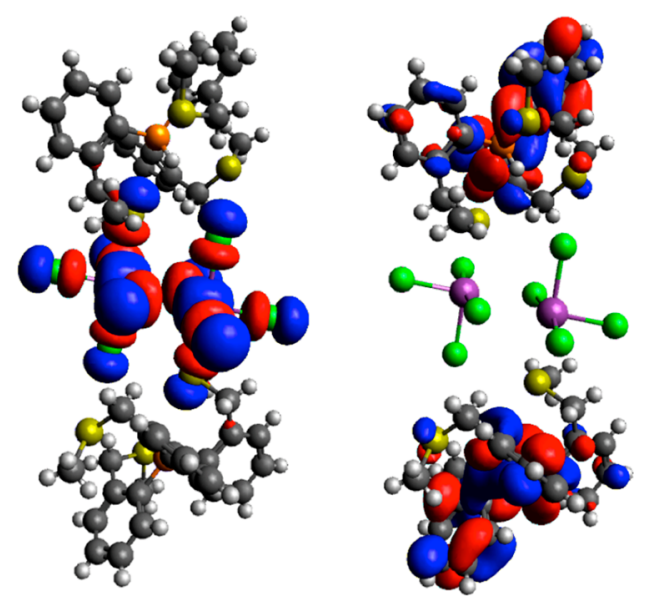

Figure 3. Kohn-Sham HOMO (left) and LUMO (right) of $\mathbf{1 A}$ at the B3LYP/def2-SVP level with a contour value of 0.02 .

halide centers increase in the order $\mathrm{Cl}, \mathrm{Br}$, I, the $\mathrm{HOMO}$ energies increase in the sequence $\mathbf{1 A}, \mathbf{1 B}, \mathbf{1 C}$, resulting in a decrease in the HOMO-LUMO gap $(7.84,7.67$, and $6.61 \mathrm{eV}$, respectively) and therefore in a shifting of the absorption band to longer wavelengths.

Altogether, these results show that both inorganic and organic components play an important role in the optical properties of these bis-zwitterions. Furthermore, the UV-vis absorptions can be tuned by changing the halogen substituents of the dibismuthate cores. Alternatively, the modifications of the $\pi^{*}$ type acceptor orbitals of the phosphonium system (e.g., via heterosubstitution in the $\pi$ system or introduction of more extended aromatic units) could be employed to further tune the optical properties of such bis-zwitterionic assemblies.

Structural Investigations: X-ray Diffraction and DFT Calculations. The inorganic/organic hybrid bis-zwitterion $\mathbf{1 A}$ crystallizes in two different polymorphic forms $\left(\mathbf{1 A}^{\prime}\right.$ and $\left.\mathbf{1} \mathbf{A}^{\prime \prime}\right)$ with the same space group $P 2_{1} / n$ and broadly similar crystal packing and lattice parameters (Table S1) but different molecular conformations. Form $\mathbf{1} \mathbf{A}^{\prime}$ is enantiotropic, undergoing a reversible, single-crystal to single-crystal phase transition between 220 and $200 \mathrm{~K}$ to the triclinic (space group $P \overline{1}$ ) form $1 \mathbf{A}^{\prime \prime \prime}$. Since the structure of $\mathbf{1 A}^{\prime \prime \prime}$ shows close similarity to that of $1 \mathbf{A}^{\prime}$, in the following only $1 \mathbf{A}^{\prime}$ and $1 \mathbf{A}^{\prime \prime \prime}$ are discussed in detail, and the polymorphic form $\mathbf{1 A}^{\prime \prime \prime}$ is presented in the Figure S13 in the Supporting Information. All of these polymorphs show discrete dimeric molecules without short contacts or significant van der Waals interactions between them.

Both dimeric $\mathbf{1} \mathbf{A}^{\prime}$ and $\mathbf{1} \mathbf{A}^{\prime \prime}$ (Figure 4A,B, respectively) adopt a bis-zwitterionic structure consisting of two $\left[\mathrm{HPS}_{3}\right]^{+}$ phosphonium units each coordinating with one thioether arm to a central dianionic $\left[\mathrm{Bi}_{2} \mathrm{Cl}_{8}\right]^{2-}$ motif, confirming that the chloride anions from the hydrogen chloride starting material are captured in the coordination spheres of the bismuth centers. The centrosymmetric core shows an edge-shared bioctahedral structure of the type $\left[\mathrm{Bi}_{2} \mathrm{X}_{8} \mathrm{~L}_{2}\right]^{2-}$ (cf. Figure 1). The two bismuth centers and six of the chloro ligands are nearly coplanar, while two further chlorines and the sulfur donors of two different $\mathbf{P S}_{3}$ ligands occupy the axial positions. Again, in both polymorphic forms these sulfur atoms are mutually trans oriented and are cis relative to the bridging chlorides. 

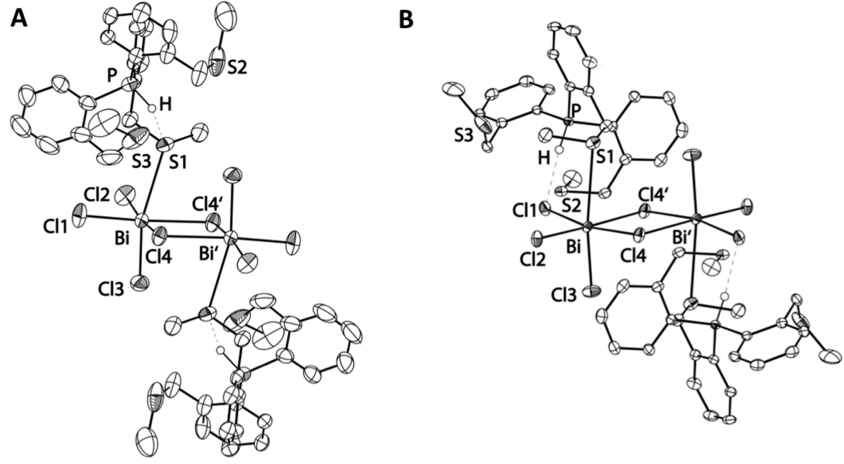

Figure 4. ORTEP representations and selected atomic distances $(\AA)$

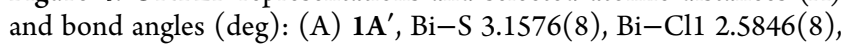
$\mathrm{Bi}-\mathrm{Cl} 2$ 2.5457(8), Bi-Cl3 2.5471(9), Bi-Cl4 2.9055(8), Bi-Cl4' $2.8192(7), \mathrm{C}-\mathrm{P}-\mathrm{C}$ bond angles 108.63(15), 110.03(14), 112.17(13); (B) $\mathbf{1 A}^{\prime \prime}, \mathrm{Bi}-\mathrm{S} 1$ 3.2416(6), Bi-Cl1 2.6411(5), Bi-Cl2 2.5542(5), $\mathrm{Bi}-\mathrm{Cl} 32.5008(6), \mathrm{Bi}-\mathrm{Cl} 4$ 2.7611(5), $\mathrm{Bi}-\mathrm{Cl}^{\prime}$ 2.8957(5), $\mathrm{C}-\mathrm{P}-\mathrm{C}$ bond angles 107.23(8), 110.36(9). 111.90(9). Thermal ellipsoids are drawn at the $50 \%$ probability level. Hydrogen atoms (except for that at the phosphorus center) have been omitted for clarity. Bond valences around the bismuth centers $(s, \mathrm{vu}$; for details see text): $1 \mathbf{A}^{\prime}, \mathrm{Bi}-\mathrm{S}$ 0.194, $\mathrm{Bi}-\mathrm{Cl} 10.754, \mathrm{Bi}-\mathrm{Cl} 20.837, \mathrm{Bi}-\mathrm{Cl} 3$ 0.834, $\mathrm{Bi}-\mathrm{Cl} 4$ 0.217, $\mathrm{Bi}-\mathrm{Cl} 4^{\prime} 0.400, \sum s=3.335 ; \mathbf{1 A}^{\prime \prime}, \mathrm{Bi}-\mathrm{S} 0.154$, $\mathrm{Bi}-\mathrm{Cl} 1$ 0.647, Bi-Cl2 0.818, Bi-Cl3 0.945, Bi-Cl4 0.468, Bi-Cl4' $0.325, \sum s=3.358$.

The question of stereochemical activity or inactivity of the lone electron pair may arise in connection with bismuth(III) cations. In contrast to the lighter congeners $\mathrm{P}$ or $\mathrm{Sb}$, the inertness (steriochemical activity) of the lone pair at $\mathrm{Bi}$ (III) centers is less pronounced and it is often difficult to recognize and verify, especially in hexacoordinated species. ${ }^{61,62}$ As the coordination environment around the bismuth centers in both $\mathbf{1} \mathbf{A}^{\prime}$ and $\mathbf{1} \mathbf{A}^{\prime \prime}$ is distorted from the ideal octahedral environment, we inspected the bond angles more closely in order to find evidence of stereochemical activity. A significant deviation from the octahedral bond angles may be indicative of the existence of an inert lone pair, and the largest distortion from the ideal geometry was found for the $\mathrm{Cl} 1-\mathrm{Bi}-\mathrm{Cl} 3$ angle in $1 \mathbf{A}^{\prime}$ : namely, $98.8^{\circ}$. On the basis of a comparison of our system to previously reported structures with stereochemically active $^{63,64}$ or inactive ${ }^{65,66}$ bismuth lone pairs, we may consider that the bismuth lone pairs in this study have no appreciable stereochemical activity. The situation is further disturbed by the fact that two different kinds of atoms $(\mathrm{S} / \mathrm{Cl})$ coordinate to the bismuth centers, which clearly affects the bonding parameters (bond lengths and bond angles). According to Wheeler et al. the stereochemical activity of the lone pair at $\mathrm{Bi}$ is consistent with an unsymmetrical distortion of the HOMO; ${ }^{61}$ however, on the basis of Figure 3 the $\mathrm{Bi}$ center in $\mathbf{1 A}$ is stereochemically inactive.

A difference between the two polymorphs shown in Figure 4 is that $\mathbf{1 A}^{\prime \prime}$ exhibits a $\mathrm{PH} \cdots \mathrm{Cll}$ hydrogen bond between the phosphonium proton and one of the terminal chloro ligands of the dibismuthate core, while in $\mathbf{1 A}^{\prime}$ only a $\mathrm{PH} \cdots \mathrm{S} 1$ interaction can be found. The presence of the $\mathrm{PH}$-.. Cl1 intramolecular hydrogen bond in $\mathbf{1 A}^{\prime \prime}$ also affects the orientation of the $\left[\mathrm{HPS}_{3}\right]^{+}$moiety with respect to the halobismuthate core.

For the metric parameters, in structure $\mathbf{1 A}^{\prime}$ the bridging $\mathrm{Bi}-$ $\mathrm{Cl}$ bond distances are, as expected, significantly longer than either the terminal or the axial distances, and the values match those observed for example in $\left[\mathrm{Li}(\mathrm{THF})_{4}\right]_{2}\left[\mathrm{Bi}_{2} \mathrm{Cl}_{8}\right]{ }^{23}$ The
$\mathrm{Bi}-\mathrm{S} 1$ bond length of $3.1576(8) \AA$ is slightly longer than that in the only reported octaiododibismuthate complex with $\mathrm{SMe}_{2}$ (3.054(8) $\AA) .{ }^{45}$ In general, the structural parameters of $\mathbf{1} \mathbf{A}^{\prime \prime}$ are similar to those of $\mathbf{1 A}^{\prime}$. The only remarkable differences are related to the previously mentioned $\mathrm{PH} \cdots \mathrm{Cll}$ hydrogen bond in the former, which leads to a slight elongation of the $\mathrm{Bi}-\mathrm{Cl} 1$ bond $(2.6411(5) \AA)$ in comparison to the other terminal $\mathrm{Bi}-$ $\mathrm{Cl} 2$ bond $(2.5542(5) \AA)$.

The bond valences $(s)$ were calculated on the basis of the method by Brown ${ }^{67}$ employing the data set reported by Brese and O'Keeffe. ${ }^{68}$ In both structures $\mathbf{1} \mathbf{A}^{\prime}$ and $\mathbf{1 A}^{\prime \prime}$, the bond valences for the bridging $\mathrm{Bi}-\mathrm{Cl}$ bonds $(s=0.317-0.468$ valence units (vu)) are significantly smaller than those of the terminal bonds $(s=0.647-0.945 \mathrm{vu})$, outlining weaker covalent interactions for the former. The bond valences of the $\mathrm{Bi}-\mathrm{S}$ interaction are $s=0.194$ and $0.154 \mathrm{vu}$ for $\mathbf{1 A}^{\prime}$ and $\mathbf{1 A}^{\prime \prime}$, respectively, and indicate a dative bond with nonnegligible covalent character. The sums of bond valences around the bismuth center in $\mathbf{1} \mathbf{A}^{\prime}$ and $\mathbf{1} \mathbf{A}^{\prime \prime}\left(\sum s=3.335\right.$ and $3.358 \mathrm{vu}$, respectively) are similar to that of the starting material $\mathrm{PS}_{3} \mathrm{BiCl}_{3}\left(\sum s=3.233 \mathrm{vu}\right) .^{58}$

The gas-phase optimized structure of $\mathbf{1 A}$ (at the $\omega \mathrm{B} 97 \mathrm{XD} /$ def2-SVP(PCM) level; see the Supporting Information) resembles that of $\mathbf{1 A}^{\prime}$ in the solid state. The Wiberg bond indices (WBI) follow the tendencies of the bond valences. The sum of NPA (natural population analysis) charges for the $\left[\mathrm{Bi}_{2} \mathrm{Cl}_{8}\right]$ moiety is $-2.13 \mathrm{e}$ (instead of $-2 \mathrm{e}$ ), which reveals electron donation from the sulfur atoms to the bismuth centers. The bis-zwitterionic charge distribution of $\mathbf{1 A}$ is clearly visible on the molecular electrostatic potential map plotted on the van der Waals surface (Figure 5).

The mixed halide analogues $\mathbf{1 B}$ and $\mathbf{1 C}$ exhibit molecular structures similar to that of the polymorph $\mathbf{1 A}^{\prime}$, and the ORTEP representations are shown in Figures S14 and S15, respectively, in the Supporting Information. The crystal structure of $1 \mathrm{C}$ (monoclinic space group $P 2_{1} / n$ ) is also similar

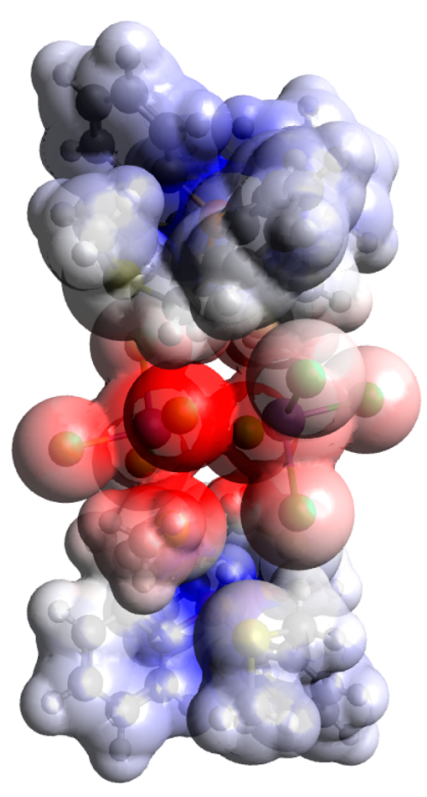

Figure 5. Molecular electrostatic potential map of $\mathbf{1 A}$ at the $\omega \mathrm{B} 97 \mathrm{XD} /$ def2-SVP(PCM) level. The red and blue areas indicate attractive and repulsive electrostatic potentials toward a positive point charge, respectively. 


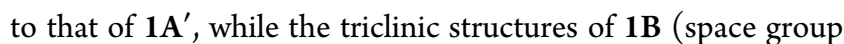
$P \overline{1})$ are analogous to that of $\mathbf{1 A}^{\prime \prime \prime}$ : i.e., distorted $\mathbf{1 A}^{\prime}$. The occupancies were refined independently for each halogen site, and the different halides show no remarkable preference at each of the positions. While for $\mathbf{1 B}$ the bromine to chlorine ratio is near to that expected (5.94:2.06), in $\mathbf{1 C}$ the $\mathrm{I}: \mathrm{Cl}$ ratio (7.19:0.81) deviates significantly from 6:2. In both $\mathbf{1 B}$ and 1C no evidence of stereochemically active lone pairs at the $\mathrm{Bi}$ (III) centers is visible.

To gain information on the relative energy of geometrical isomers of the mixed halides with the formula $\left[\mathrm{HPS}_{3} \mathrm{BiX}_{3} \mathrm{Cl}\right]_{2}$ (with both $\mathrm{X}=\mathrm{Br}$ and $\mathrm{X}=\mathrm{I}$ ), the structures of 10 possible geometrical (cis/trans) isomers were generated by placing one chlorine atom at each bismuth center at different positions (bridging, axial, or any equatorial) and the optimized results at the $\omega \mathrm{B} 97 \mathrm{XD} / \mathrm{def} 2-\mathrm{SVP}(\mathrm{PCM})$ level are collected in the Supporting Information. In the case of the bromine analogue all 10 isomers have rather similar relative energies and the maximum difference is only $3.1 \mathrm{kcal} / \mathrm{mol}$ (see Table S4), which agrees with the observed equal distribution of the different halides in the solid-state structures. In contrast, the relative energy difference among the 10 geometrical isomers is somewhat larger $(6.9 \mathrm{kcal} / \mathrm{mol})$ in the case of the iodine analogue. On the basis of the relative energies, the chlorine atoms disfavor the bridging positions and prefer the axial or equatorial positions (for details see Table S5).

The adduct of $\mathbf{P S}_{3} \mathrm{BiCl}_{3}$ and $\mathrm{Ag}(\mathrm{OTf})$ forms a onedimensional polymeric chain with the formula $\left\{\left[\mathrm{AgPS}_{3} \mathrm{BiCl}_{3}(\mathrm{OTf})\right]_{2}\left(\mathrm{CH}_{3} \mathrm{CN}\right)_{2}\right\}_{\infty}$ (Figure 6A). Between
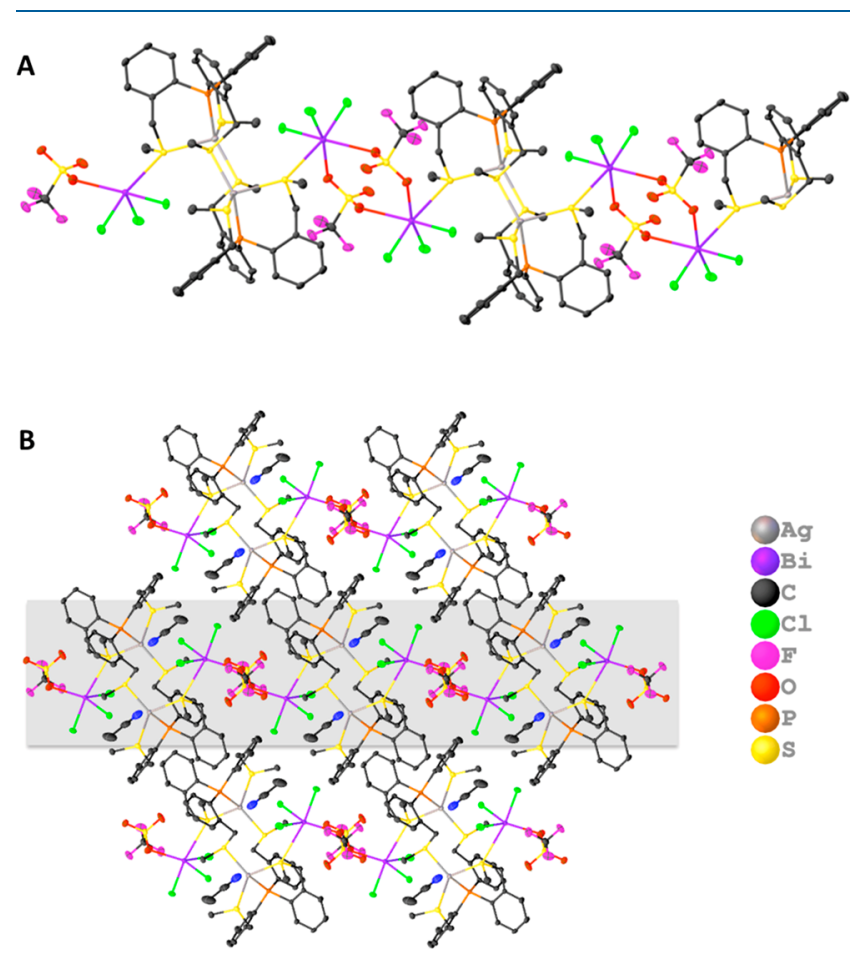

Figure 6. (A) ORTEP representation showing the ribbonlike polymeric chain of $\left\{\left[\mathrm{AgPS}_{3} \mathrm{BiCl}_{3}(\mathrm{OTf})\right]_{2}\left(\mathrm{CH}_{3} \mathrm{CN}\right)_{2}\right\}_{\infty}$ composed of dibismuthate units $\left[\mathrm{Bi}_{2} \mathrm{Cl}_{8}\right]^{2-}$ and cationic $\left[\mathrm{Ag}\left(\mathrm{PS}_{3}\right)\right]_{2}{ }^{2+}$. Hydrogen atoms and solvent molecules have been omitted for clarity. (B) Packing representation of $\left\{\left[\mathrm{AgPS}_{3} \mathrm{BiCl}_{3}(\mathrm{OTf})\right]_{2}\left(\mathrm{CH}_{3} \mathrm{CN}\right)_{2}\right\}_{\infty}$ along the $a$ axis. Hydrogen atoms are not shown. The gray area represents the polymeric chain shown in A. Thermal ellipsoids are drawn at the $50 \%$ probability level in both images. the polymeric chains no significant van der Waals interactions can be found. Along the $a$ axis a void contains acetonitrile solvent molecules (Figure 6B). In this polymer, dibismuthate building blocks with the formula $\left[\mathrm{Bi}_{2} \mathrm{X}_{6} \mathrm{Y}_{2} \mathrm{~L}_{2}\right]^{2-}$ (Figure 1) can be found. While 1A-C contain discrete bis-zwitterions, the silver/bismuth heterometallic polymer is built up by an infinite chain of dianionic and dicationic repeating units (triflatobridged dibismuthates and $\left[\mathrm{Ag}\left(\mathbf{P S}_{3}\right)\right]_{2}{ }^{2+}$ macrocycles, respectively). In contrast to the more common polymeric bismuthate ions outlined in the Introduction, ${ }^{3,5}$ in the present case discrete dibismuthate anions are the repeating units connecting dicationic macrocycles via organic linkers.

The question may arise as to how strong is the interaction which holds together the assembly of the polymeric chain. The heterolytic bond dissociation energy of an $\mathrm{S} \rightarrow \mathrm{Bi}$ dative bond amounts to only $14.3 \mathrm{kcal} / \mathrm{mol}$ (as calculated for $\mathrm{Me}_{2} \mathrm{~S} \rightarrow \mathrm{BiCl}_{3}$ at the $\omega \mathrm{B} 97 \mathrm{XD} / \mathrm{def} 2-\mathrm{SVP}$ level), which implies that the formation of such bonds can be reversible. We have estimated the (BSSE corrected) total interaction energy associated with the assembly of two neutral $\left[\left(\mathrm{AgPS}_{3}\right)_{2} \mathrm{Bi}_{2} \mathrm{Cl}_{6}(\mathrm{OTf})_{2}\right]$ units (as depicted in Scheme 2) via an $\mathrm{S} \rightarrow \mathrm{Bi}$ bond (to form $\left.\left[\left(\mathrm{AgPS}_{3}\right)_{2} \mathrm{Bi}_{2} \mathrm{Cl}_{6}(\mathrm{OTf})_{2}\right]_{2}\right)$, which is as large as $46.6 \mathrm{kcal} / \mathrm{mol}$ $(\omega \mathrm{B} 97 \mathrm{XD} / \mathrm{def} 2-\mathrm{SVP}$, employing solid-state structures as references). This shows that, in addition to the dative bond, significant electrostatic attraction arises between the partial charges of the fragments. Nevertheless, due to the heterolytic dissociation of the dative $\mathrm{S} \rightarrow \mathrm{Bi}$ bond, the solution of compound 2 presumably contains $\left[\mathrm{AgPS}_{3} \mathrm{BiCl}_{3}(\mathrm{OTf})\right]$ or its dimeric form rather than a polymer, as suggested by DOSY experiments (for details see the Supporting Information).

In the centrosymmetric $\left[\mathrm{Bi}_{2} \mathrm{Cl}_{6}(\mathrm{OTf})_{2}\right]^{2-}$ core (Figure $7 \mathrm{~A}$ ), the triflate anions occupy the bridging positions and, similarly to $\mathbf{1 A - C}$, the sulfur donor atoms in the octahedral coordination sphere of the bismuth are mutually trans oriented. The $\mathrm{Bi}-\mathrm{Cl}$ bond lengths in the dibismuthate $\left[\mathrm{Bi}_{2} \mathrm{Cl}_{6}(\mathrm{OTf})_{2}\right]^{2-}$

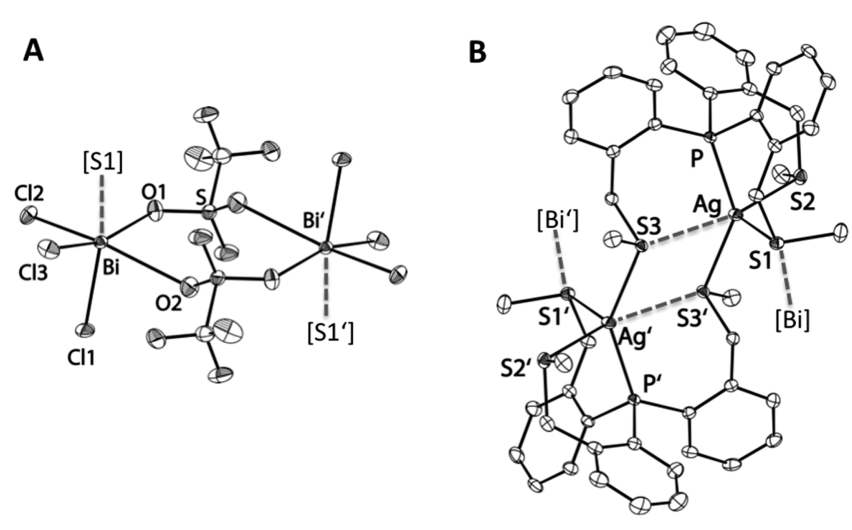

Figure 7. OR TEP representations of $\left\{\left[\mathrm{AgPS}_{3} \mathrm{BiCl}_{3}(\mathrm{OTf})\right]_{2}\left(\mathrm{CH}_{3} \mathrm{CN}\right)_{2}\right\}_{\infty}$ and selected atomic distances $(\AA)$ and bond angles (deg): (A) $\left[\mathrm{Bi}_{2} \mathrm{Cl}_{6}(\mathrm{OTf})_{2}\right]^{2-}, \mathrm{Bi}-\mathrm{O} 1$ 2.7564(17), Bi-O2 2.776, Bi-S1 3.2304(5), Bi-Cl1 2.4918(6), $\mathrm{Bi}-\mathrm{Cl} 2$ 2.4808(6), $\mathrm{Bi}-\mathrm{Cl} 32.4949(5) ;(\mathrm{B})\left[\mathrm{Ag}\left(\mathrm{PS}_{3}\right)\right]_{2}{ }^{2+}, \mathrm{Ag}-\mathrm{P}$ 2.4658(5), Ag-S1 2.6823(5), Ag-S2 2.5854(5), Ag-S3' 2.5050(5), Ag...S3 3.418. Thermal ellipsoids are drawn at the $50 \%$ probability level. Hydrogen atoms and solvent molecules have been omitted for clarity. Bond valences ( $s$, vu; for details see the text): around the bismuth centers, Bi-S1 0.159, Bi-Cl1 0.969, Bi-Cl2 0.998, Bi-Cl3 $0.961, \mathrm{Bi}-\mathrm{O} 10.165, \mathrm{Bi}-\mathrm{O} 20.157, \sum s=3.408$; around the silver centers, Ag-P 0.515, Ag-S1 0.237, Ag-S2 0.308, Ag-S3' 0.383, $\mathrm{Ag} \cdots \mathrm{S} 3$ 0.032, $\sum s=1.476$. 
are shorter than those observed in the polymorphs of $1 \mathbf{A}$ (vide supra), and the larger bond valences also show a strengthening of these bonds (see legend of Figure 7). The $\mathrm{Bi}-\mathrm{O}$ distances (on average $2.77 \AA$ ) are significantly shorter than the sum of the van der Waals radii of $\mathrm{Bi}$ and $\mathrm{O}(3.59 \AA)^{69}$ and are in the range of those observed in other Bi-triflate structures. ${ }^{46,58}$ Nevertheless, the bond valences of the $\mathrm{Bi}-\mathrm{O}$ interactions (on average $s=0.16 \mathrm{vu}$ ) only indicate weak coordination of the triflate anions, enabling the three terminal chlorides to build up a stronger coordination than in dibismuthate 1A. Hence, the total occupancy of the coordination sphere around the bismuth center in $\left[\mathrm{Bi}_{2} \mathrm{Cl}_{6}(\mathrm{OTf})_{2}\right]^{2-}$ is similar to that in $\mathbf{1 A}$, which is also reflected in the similar sum of bond valences $\left(\sum s=3.408\right.$ vu in comparison to $\sum s=3.335$ and 3.358 vu in $\mathbf{1 A}^{\prime}$ and $\mathbf{1} \mathbf{A}^{\prime \prime}$, respectively). In order to clarify the degree of stereochemical activity of the lone pair at the bismuth center, again the bond angles were examined around the central atom and compared with literature examples (vide supra). Significantly, the O1$\mathrm{Bi}-\mathrm{S}$ bond angle $\left(108.5^{\circ}\right)$ shows a substantial deviation from the ideal $90^{\circ}$. Therefore, in contrast to the bis-zwitterionic dimers 1A-C discussed above, the lone pair at the bismuth center in this silver complex exhibits a considerable stereochemical activity, pointing between the $\mathrm{O} 1$ and $\mathrm{S}$ atoms.

The tetradentate $\mathbf{P S}_{3}$ ligand coordinates in a scorpionate fashion with three dative interactions $(\mathrm{P} \rightarrow \mathrm{Ag}, \mathrm{S} 1 \rightarrow \mathrm{Ag}$, and $\mathrm{S} 2 \rightarrow \mathrm{Ag}$ ) and a weak $\mathrm{S} 3 \cdots \mathrm{Ag}$ interaction to the same silver center, while the last sulfur center is also involved in a bridging $\mathrm{S} 3 \rightarrow \mathrm{Ag}^{\prime}$ bond to the second silver cation. The $\mathrm{Ag}-\mathrm{P}$ bond length $(2.4658(5) \AA)$ is in the expected range for silver

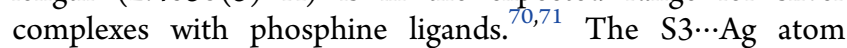
distance $(3.418 \AA)$ is clearly shorter than the sum of van der Waals radii of these elements $(3.8 \AA),,^{72}$ and these weak interactions act as cross-connections to stabilize the 12membered $\mathrm{Ag}_{2} \mathrm{P}_{2} \mathrm{~S}_{2} \mathrm{C}_{6}$ "macrocycle". The dative $\mathrm{S} \rightarrow \mathrm{Ag}$ bond lengths are similar to previously reported bond lengths. Among these, the $\mathrm{S} 1 \rightarrow \mathrm{Ag}$ bond is the longest, because the S1 center binds in a bridging $\mu_{2}$ fashion between the silver and the adjacent bismuth center, linking the dianionic and dicationic parts (Figure 7B). The bond valences show that the interaction of the silver with the phosphorus center $(s=0.515 \mathrm{vu})$ is stronger than that with the sulfur atoms $(s=0.032-0.383 \mathrm{vu})$.

The gas-phase optimized structure of the dicationic $\left[\mathrm{Ag}\left(\mathbf{P S}_{3}\right)\right]_{2}{ }^{2+}\left(\omega \mathrm{B} 97 \mathrm{XD} / \mathrm{def} 2-\mathrm{SVP}\left(\mathrm{PCM}=\mathrm{CH}_{2} \mathrm{Cl}_{2}\right)\right.$; for details see Table S6) is very similar to that observed in the solid state. An atoms in molecules (AIM) analysis of the $\left[\mathrm{Ag}\left(\mathbf{P S}_{3}\right)\right]_{2}{ }^{2+}$ dication (see Figure 8) located five bond critical points around each of the silver centers. The electron density at the bond critical points shows the same tendency as that observed for the bond valences. Importantly, the sign of the total electronic energy density ${ }^{73,74}$ at the bond critical point $(H)$ reveals a difference between the four dative bonds and the fifth weaker $S \cdots A$ Ag interaction (shown with blue arrows in Figure 8). In the case of the former dative bonds $H<0$ indicates high covalent character (clearly a dative interaction), while for the latter $H>0$ suggests a noncovalent van der Waals interaction. Therefore, the fifth, weakest S...Ag interaction is best described as a van der Waals interaction rather than a dative bond. Note that recently the concept of $\sigma$-hole interactions has also been extended to coinage metals (coinage-metal bond or regium bond) $)^{75-77}$ and group 12 metals (spodium bonds). ${ }^{78}$

Altogether, the silver center in the centrosymmetric dicationic $\left[\mathrm{Ag}\left(\mathbf{P S}_{3}\right)\right]_{2}{ }^{2+}$ macrocycle (Figure $7 \mathrm{~B}$ ) is stabilized

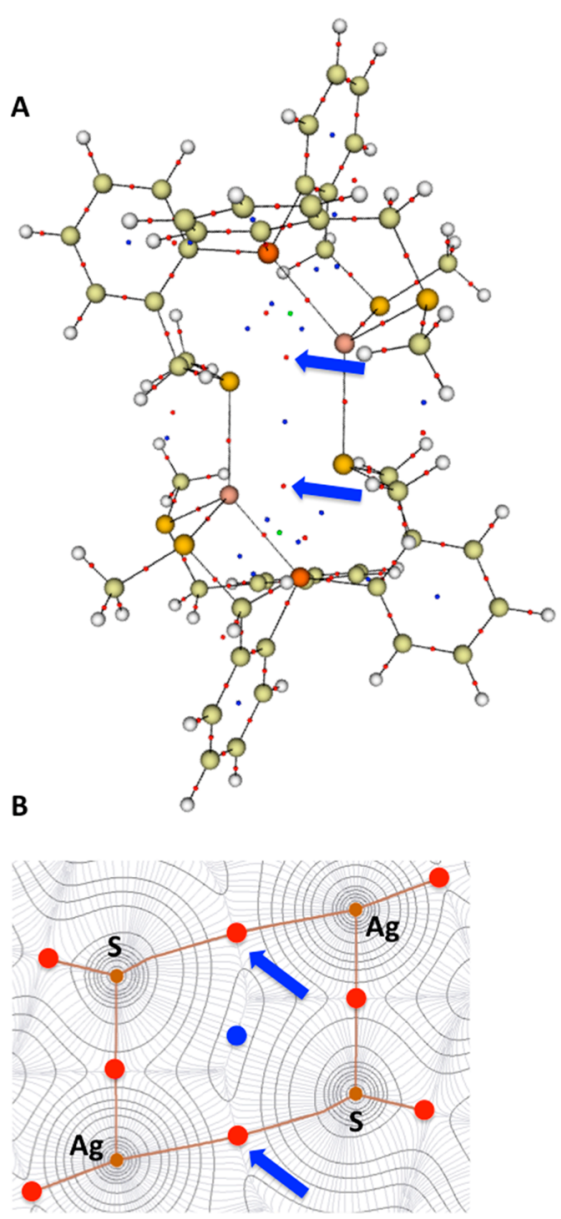

Figure 8. Plots of the results obtained by AIM analysis of the dimer $\left[\mathrm{Ag}\left(\mathrm{PS}_{3}\right)\right]_{2}{ }^{2+}$ at the $\omega \mathrm{B} 97 \mathrm{XD} / \mathrm{def} 2-\mathrm{SVP}\left(\mathrm{PCM}=\mathrm{CH}_{2} \mathrm{Cl}_{2}\right)$ level of theory. Red, blue, and green dots indicate bond, ring, and cage critical points, respectively. The blue arrows show the weak $S \cdots \mathrm{Ag}$ interactions. (A) Three-dimensional representation of bond, ring, and cage critical points. (B) Contour plot of the electron density in the $\mathrm{Ag}_{2} \mathrm{~S}_{2}$ plane.

by coordination of one phosphorus and three sulfur donors as well as a further van der Waals S...Ag interaction. On the basis of the four dative bonds the silver centers could be considered as 4-coordinated. On the other hand, the number of bond critical points representing the interactions suggests a coordination number of 5 . In analogy with the limited number of reported examples with 5-coordinated silver centers, ${ }^{79-88}$ we therefore describe the silver centers in the $\left[\operatorname{Ag}\left(\mathbf{P S}_{3}\right)\right]_{2}{ }^{2+}$ units as 5-coordinated. The structural parameter value of $\tau_{5}=0.47$ indicates that the coordination around the silver atom is intermediate between trigonal bipyramidal and square pyramidal. ${ }^{89,90}$

${ }^{31} \mathrm{P}$ NMR Experiments and Thermodynamic Considerations. As described above, the reaction of $\mathrm{PS}_{3} \mathrm{BiX}_{3}(\mathrm{X}=$ $\mathrm{Cl}, \mathrm{Br}, \mathrm{I})$ with $\mathrm{HCl}$ delivers the bis-zwitterionic compounds 1A-C. This reaction involves the heterolytic splitting of $\mathrm{HCl}$, accompanied by the coordination of the $\mathrm{Cl}^{-}$anion to the $\mathrm{Bi}$ center and the protonation of the phosphorus. The latter is clearly visible in the ${ }^{31} \mathrm{P}$ NMR spectrum, which contains a doublet resonance at $-20.8 \mathrm{ppm}$ with a ${ }^{1} J\left({ }^{31} \mathrm{P}-{ }^{1} \mathrm{H}\right)$ coupling constant of $535 \mathrm{~Hz}$. In general, phosphines are known to be weak Brønsted bases in organic solvents: e.g., for triphenyl- 
phosphine $\mathrm{pK}_{\mathrm{a}}\left(\mathrm{HPPh}_{3}{ }^{+}\right)=7.64$ in acetonitrile $\mathrm{e}^{91}$ and has an estimated value in THF of $3 . .^{92}$

The protonation of phosphines with hydrogen halides $\mathrm{HX}$ to form the triorganylphosphonium halide $\left[\mathrm{HPR}_{3}\right]^{+} \mathrm{X}^{-}$strongly depends on the basicity of the phosphines and the strength of the acids. According to the solid-state studies, the triethylphosphononium salt $\left[\mathrm{HPEt}_{3}\right]^{+} \mathrm{X}^{-}$exists with $\mathrm{X}=\mathrm{Cl}, \mathrm{Br}, \mathrm{I}$; however, the triphenyl analogue $\left[\mathrm{HPPh}_{3}\right]^{+} \mathrm{X}^{-}$is only known with $\mathrm{X}=\mathrm{Br}$, I counterions. This is due to the lower basicity of triphenylphosphine in comparison to triethylphosphine ${ }^{93}$ and the weaker acidity of $\mathrm{HCl}$ in comparison to $\mathrm{HBr}$ and $\mathrm{HI}$. Sheldon and Tyree reported the reaction product of triphenylphosphine and $\mathrm{HCl}$ with the formula $\left[\mathrm{Ph}_{3} \mathrm{PHCl}\right]_{3}$. $\mathrm{HCl}^{94}$ Later on, however, van den Akker and Jellinek showed that this adduct arose from the partial decomposition of the labile hydrogendichloride salt $\left[\mathrm{HPPh}_{3}\right]^{+}\left[\mathrm{HCl}_{2}\right]^{-}$(which readily decomposed finally to $\mathrm{PPh}_{3}$ and $\left.2 \mathrm{HCl}\right) .{ }^{93}$ Clearly, a second molecule of $\mathrm{HCl}$ is necessary to capture the chloride anion in the form of hydrogendichloride $\left[\mathrm{HCl}_{2}\right]^{-}$to facilitate the protonation. Alternatively, strong Lewis acids such as $\mathrm{Sn}(\mathrm{IV})$, $\mathrm{Fe}(\mathrm{III})$, and $\mathrm{Mo}$ (III) can also be employed as chloride scavengers to form ionic phosphonium salts in the solid state. ${ }^{94,95}$

In contrast to the observations for the solid state, in solution, the reaction of phosphines with hydrogen halides typically results in an equilibrium: $\mathrm{R}_{3} \mathrm{P}+\mathrm{HX} \rightleftharpoons\left[\mathrm{R}_{3} \mathrm{PH}\right]^{+}+\mathrm{X}^{-}$. For example, even $\mathrm{HBr}$, which is a stronger acid in comparison to $\mathrm{HCl}$, can only protonate triphenylphosphine reversibly, resulting in a broad resonance without resolved ${ }^{1} J\left({ }^{31} \mathrm{P}-{ }^{1} \mathrm{H}\right)$ coupling in the ${ }^{31} \mathrm{P}$ NMR spectra. ${ }^{96}$ Furthermore, the corresponding chemical shift represents a superposition between those of the protonated and nonprotonated phosphine. This reversibility is due to the competing affinities of the phosphine and the rather basic halide anion toward the same $\mathrm{H}^{+}$. The protonation of phosphines with $\mathrm{HCl}$ in organic solvents requires special conditions, and to our knowledge only two studies have reported on this. One possibility is to activate $\mathrm{HCl}$ via capturing the chloride ion: for example, by a hydrogen-bonding network (to the thiourea moiety $\mathrm{R}-\mathrm{NH}-$ $\left.\mathrm{C}(\mathrm{S})-\mathrm{NH}-\mathrm{R}^{\prime}\right) .{ }^{9}$ Alternatively, the proton of $\mathrm{HCl}$ can be encapsulated into a rigid and sterically congested cage at the $\mathrm{P}$ center with further stabilization of hydrogen bonding to another phosphorus (as reported for an in, in diphosphine). ${ }^{98}$ In light of these studies, the selective formation of compounds 1A-C prompted us to investigate these reactions further.

To gain more insights as to why the protonation shown in Scheme 1 does not lead to an equilibrium, we performed NMR experiments in which the roles of the ligand and the bismuth center were separately considered. We also performed DFT calculations employing the $\omega \mathrm{B} 97 \mathrm{XD}$ functional with different basis sets to further bolster the experimental studies. In the following we only discuss the results obtained at the $\omega \mathrm{B} 97 \mathrm{XD} /$ (aug-)cc-pVDZ(-PP) level, which has been used successfully for similar systems before. ${ }^{56}$ The solvent effects were simulated using the polarizable continuum model (PCM) with dichloromethane as solvent.

First, we checked whether the $\mathbf{P S}_{3}$ ligand is basic enough to be protonated with $\mathrm{HCl}$ in the absence of $\mathrm{BiCl}_{3}$. The reaction of the free ligand $\mathbf{P S}_{3}$ with an excess of $\mathrm{HCl}$ yields a broad singlet peak at $-32.0 \mathrm{ppm}$ in the ${ }^{31} \mathrm{P}$ NMR spectrum of the $\mathrm{CD}_{2} \mathrm{Cl}_{2}$ solution. This chemical shift is situated between those of the protonated form $1 \mathrm{~A}\left(-20.8 \mathrm{ppm}\right.$ in $\left.\mathrm{CD}_{2} \mathrm{Cl}_{2}\right)$ and the (nonprotonated) free ligand $\mathbf{P S}_{3}\left(-36.2 \mathrm{ppm}\right.$ in $\left.\mathrm{CD}_{2} \mathrm{Cl}_{2}\right)$, and the unresolved broad peak indicates an equilibrium (Figure $9 a-c)$. On the basis of the gas-phase proton affinities, the

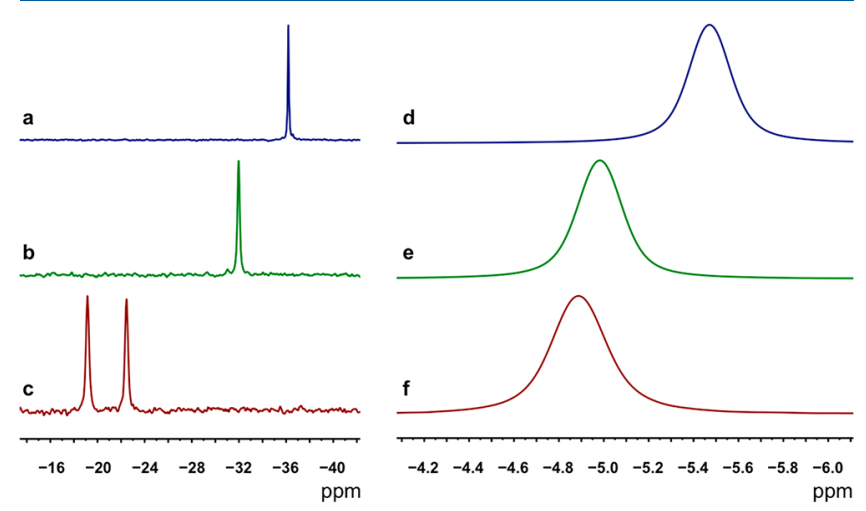

Figure 9. Solution ${ }^{31} \mathrm{P}$ NMR spectra of (a) $\mathbf{P S}_{3}$, (b) $\mathbf{P S}_{3}+\mathrm{HCl}$, (c) 1A, (d) $\mathrm{PPh}_{3}$, (e) $\mathrm{PPh}_{3}+\mathrm{HCl}$, and (f) $\mathrm{PPh}_{3}+\mathrm{HCl}+\mathrm{BiCl}_{3}:(\mathrm{a}-\mathrm{c})$ in $\mathrm{CD}_{2} \mathrm{Cl}_{2}$; (d, e) in dioxane; (f) in a dioxane/ $\mathrm{CH}_{2} \mathrm{Cl}_{2}(1 / 1)$ mixture.

ligand PS $_{3}(-252.2 \mathrm{kcal} / \mathrm{mol})$ is somewhat more basic than tri$o$-tolylphosphine $(-244.5 \mathrm{kcal} / \mathrm{mol})$ or triphenylphosphine $(-241.1 \mathrm{kcal} / \mathrm{mol})$. However, this slightly higher basicity of $\mathbf{P S}_{3}$ is apparently not enough to compete with the chloride anion for the proton (see above).

Second, we aimed to clarify whether the chloride affinity (Lewis acidity) of $\mathrm{BiCl}_{3}$ facilitates the protonation of a phosphine with hydrogen chloride in the form of $\left[\mathrm{HPR}_{3}\right]^{+}\left[\mathrm{BiCl}_{4}\right]^{-}$. Therefore, solutions of triphenylphosphine and $\mathrm{HCl}$ were combined, and in a second step, $\mathrm{BiCl}_{3}$ was added to this solution. In both cases, only broad singlet peaks shifted slightly downfield in comparison to triphenylphosphine were observed and no spin-spin ${ }^{1} J\left({ }^{31} \mathrm{P}-{ }^{1} \mathrm{H}\right)$ coupling was detected (Figure $9 \mathrm{~d}-\mathrm{f}$ ). This indicates that $\mathrm{BiCl}_{3}$ is not effective enough to capture the $\mathrm{Cl}^{-}$from $\mathrm{HCl}$, which is in line with the lability of the $\left[\mathrm{BiCl}_{4}\right]^{-}$anion (the stability constant of the reaction $\mathrm{BiCl}_{3}+\mathrm{Cl}^{-} \rightleftharpoons \mathrm{BiCl}_{4}^{-}$is only $\left.\mathrm{K}=2.7 \pm 1\right){ }^{2}$ We have estimated the chloride anion affinity of bismuth trichloride by computing the following reaction $\mathrm{BiCl}_{3}+\mathrm{Cl}^{-}$ $\rightleftharpoons \mathrm{BiCl}_{4}{ }^{-}$, and the Gibbs free energy of this reaction $(-10.4$ $\mathrm{kcal} / \mathrm{mol}$ ) indicates that $\mathrm{BiCl}_{4}^{-}$seems to be more stable according to the gas-phase calculations (including solvent effects) than in the solution experiments. Nevertheless, the energetic consequences of this complexation reaction are minor in comparison to those of the protonation of the phosphine. Furthermore, our findings demonstrate the moderate Lewis acidity of $\mathrm{BiCl}_{3}$ in contrast to highly Lewis acidic bismuthenium cations or neutral bismuth triamides, as outlined by several recent experimental and computational investigations. $^{99-104}$

We may conclude from the ${ }^{31} \mathrm{P}$ NMR test experiments that the protonation with $\mathrm{HCl}$ cannot be achieved alone by either the $\mathrm{PS}_{3}$ ligand or $\mathrm{BiCl}_{3}$, and the computations suggest that the energetic effect of the protonation at the $\mathrm{P}$ center is more substantial than that of the $\mathrm{Cl}^{-}$coordination to the $\mathrm{BiCl}_{3}$ unit. So far, however, we have not considered the possible stabilizing effect of the dimerization leading to the dibismuthate core. Therefore, we computationally investigated the energetics of the reaction between $\mathrm{PS}_{3} \mathrm{BiCl}_{3}$ and $\mathrm{HCl}$ resulting in the biszwitterionic compound 1A ( $\omega$ B97XD/(aug-)cc-pVDZ(-PP)$\left(\mathrm{PCM}=\mathrm{CH}_{2} \mathrm{Cl}_{2}\right)$ level). As this reaction is associative in nature, in addition to the reaction energies we include the Gibbs free energies as well. Since the entropy in the gas-phase 
calculations is remarkably different from that expected in solution, the computed reaction Gibbs free energies only give an upper limit and we primarily focus on the reaction energies.

Presumably, in the first step of the reaction the monomeric form of dimer $\mathbf{1 A}$ arises from $\mathbf{P S}_{3} \mathrm{BiCl}_{3}$ and an $\mathrm{HCl}$ molecule, which then dimerizes to form the final product. We attempted to optimize the structure of this monomeric unit from different starting geometries, and these optimizations resulted in the contact ion pair $\left[\mathrm{HPS}_{3}\right]^{+}\left[\mathrm{BiCl}_{4}\right]^{-}$without $\mathrm{Bi}-\mathrm{S}$ close contacts. The reaction energy and Gibbs free energy of the reaction $\mathbf{P S}_{3} \mathrm{BiCl}_{3}+\mathrm{HCl} \rightarrow\left[\mathrm{HPS}_{3}\right]^{+}\left[\mathrm{BiCl}_{4}\right]^{-}$are $\Delta E=-5.8 \mathrm{kcal} / \mathrm{mol}$ and $\Delta G^{\circ}{ }_{298 \mathrm{~K}}=+2.4 \mathrm{kcal} / \mathrm{mol}$, respectively, indicating no substantial thermodynamic stabilization. In contrast, the dimerization reaction $2\left[\mathrm{HPS}_{3}\right]^{+}\left[\mathrm{BiCl}_{4}\right]^{-} \rightarrow \mathbf{1 A}$ is exothermic by $\Delta E=-34.2 \mathrm{kcal} / \mathrm{mol}\left(\Delta G^{\circ}{ }_{298 \mathrm{~K}}=-11.4 \mathrm{kcal} / \mathrm{mol}\right)$. This shows that the dimerization is an important stabilizing factor in the formation of $\mathbf{1 A}$ and likely this compound exists in its dimeric, bis-zwitterionic form in solution. The complete reaction of $2 \mathbf{P S}_{3} \mathrm{BiCl}_{3}+2 \mathrm{HCl} \rightarrow \mathbf{1 A}$ is rather exothermic $\left(\Delta E=-45.8 \mathrm{kcal} / \mathrm{mol}\right.$ and $\left.\Delta G^{\circ}{ }_{298 \mathrm{~K}}=-6.6 \mathrm{kcal} / \mathrm{mol}\right)$, which explains why this is not an equilibrium reaction. Furthermore, the importance of the $\mathbf{P S}_{3}$ ligand in this reaction is highlighted by the following hypothetical exchange reaction: $\left[\mathrm{HPPh}_{3}\right]_{2}\left[\mathrm{Bi}_{2} \mathrm{Cl}_{8}\right]+2 \mathbf{P S}_{3} \rightarrow \mathbf{1 A}+2 \mathrm{PPh}_{3}$, which indicates a remarkable stabilization in $\mathbf{1 A}\left(\Delta E=-21.0 \mathrm{kcal} / \mathrm{mol}, \Delta G^{\circ} 298 \mathrm{~K}\right.$ $=-10.0 \mathrm{kcal} / \mathrm{mol})$.

\section{CONCLUSION}

We have shown that dibismuthates can serve as bridging units for constructing bis-zwitterionic inorganic/organic hybrid assemblies as well as coordination polymers. While the $\mathbf{P S}_{3}$ ligand coordinates in a monodentate fashion in the 0dimensional bis-zwitterions, in the $1 \mathrm{D}$ coordination polymer $\left\{\left[\mathrm{AgPS}_{3} \mathrm{BiCl}_{3}(\mathrm{OTf})\right]_{2}\left(\mathrm{CH}_{3} \mathrm{CN}\right)_{2}\right\}_{\infty}$ it binds with all four donor atoms. Among these, two sulfur donors act as $\mu_{2}$ bridges: one of them cross-links the 12-membered $\mathrm{Ag}_{2} \mathrm{P}_{2} \mathrm{~S}_{2} \mathrm{C}_{6}$ "macrocycle", while the other connects the 5-coordinated silver and 6-coordinated bismuth centers. Altogether, the phosphorus and the three sulfur donor atoms endow the $\mathbf{P S}_{3}$ ligand with versatile coordination ability, complementing the previously reported tridentate and tetradentate coordination modes. ${ }^{56}$ The UV-vis absorption bands connected to excitations from the dibismuthate core into the $\pi^{*}$ system of the phosphonium units can be tuned by varying the halogen substitutions at the bismuth centers in the bis-zwitterions.

Despite the remarkable differences between hydrogen chloride and silver triflate, their reactivities toward the $\mathrm{PS}_{3} \mathrm{BiCl}_{3}$ adduct show several analogous features. (1) The connections between the ligand and the bismuth center are cleaved except for one $\mathrm{Bi}-\mathrm{S}$ bond, which acts as a linker between the cationic and anionic fragments in the final products. (2) The phosphorus center is attacked by the electrophiles $\mathrm{H}^{+}$or $\mathrm{Ag}^{+}$replacing the bismuth center. (3) The counteranions $\mathrm{Cl}^{-}$and $\mathrm{OTf}^{-}$are scavenged in the coordination sphere of the bismuth to form dibismuthate linkers.

Triarylphosphines are typically rather weak bases, and their reaction with hydrogen chloride in organic solvents leads to an equilibrium reaction. This can be explained by the competition of the phosphine and the halide anion for the proton. Remarkably, in this case the reaction does not lead to an equilibrium and the energy requirements of this process were studied by DFT calculations, which highlighted that the formation of the dimeric dibismuthate plays a major role.
To the best of our knowledge, herein we report the first coordination polymer incorporating dibismuthate units and organometallic linkers. As our study shows the potential of dibismuthates as anionic building blocks for versatile structural motifs, in the future we intend to investigate the structure and properties of further derivatives (especially with main-group and transition metals).

\section{ASSOCIATED CONTENT}

\section{Supporting Information}

The Supporting Information is available free of charge at https://pubs.acs.org/doi/10.1021/acs.inorgchem.0c01619.

Description of experimental procedures, characterization of compounds, X-ray crystallographic studies, and computational details (PDF)

\section{Accession Codes}

CCDC 1998214-1998218 and 1998469 contain the supplementary crystallographic data for this paper. These data can be obtained free of charge via www.ccdc.cam.ac.uk/data_request/ cif, or by emailing data_request@ccdc.cam.ac.uk, or by contacting The Cambridge Crystallographic Data Centre, 12 Union Road, Cambridge CB2 1EZ, UK; fax: +44 1223336033.

\section{AUTHOR INFORMATION}

\section{Corresponding Authors}

Zoltán Benkö - Budapest University of Technology and Economics, H-1111 Budapest, Hungary; (1) orcid.org/00000001-6647-8320; Email: zbenko@mail.bme.hu

Dominikus Heift - Department of Chemistry, Durham University, DH1 3LE Durham, United Kingdom; 이이.org/ 0000-0002-6799-5052; Email: dominikus.heift@ durham.ac.uk

\author{
Authors \\ Csilla Fekete - Budapest University of Technology and \\ Economics, H-1111 Budapest, Hungary \\ Jamie Barrett - Department of Chemistry, Durham University, \\ DH1 3LE Durham, United Kingdom
}

Complete contact information is available at:

https://pubs.acs.org/10.1021/acs.inorgchem.0c01619

\section{Notes}

The authors declare no competing financial interest.

\section{ACKNOWLEDGMENTS}

The authors thank Dr. A. Batsanov, Dr. P. W. Dyer, Dr. D. Yufit, Dr. G. Müller, Dr. A. Congreve, and Dr. J. A. AguilarMalavia for their help and acknowledge the support of an European Union COFUND/Durham Junior Research Fellowship under EU grant agreement number 609412, BME Nanotechnology and Materials Science TKP2020 IE grant of NKFIH Hungary (BME IE-NAT TKP2020), NKFIH (PD 116329), Janos Bolyai Research Scholarship, and a UNKP-205-BME-317 grant.

\section{DEDICATION}

Dedicated to Prof. Péter Huszthy on the occasion of his 70th birthday. 


\section{REFERENCES}

(1) Noyes, A. A.; Hall, F. W.; Beattie, J. A. The solubility of bismuth oxychloride in hydrochloric acid and its relation to complex formation. J. Am. Chem. Soc. 1917, 39 (12), 2526-2532.

(2) Newman, L.; Hume, D. N. A Spectrophotometric Study of the Bismuth-Chloride Complexes. J. Am. Chem. Soc. 1957, 79 (17), 4576-4581.

(3) Adonin, S. A.; Sokolov, M. N.; Fedin, V. P. Polynuclear halide complexes of $\mathrm{Bi}(\mathrm{III})$ : From structural diversity to the new properties. Coord. Chem. Rev. 2016, 312, 1-21.

(4) Fisher, G. A.; Norman, N. C.; Sykes, A. G. The Structures of the Group 15 Element(III) Halides and Halogenoanions. Adv. Inorg. Chem. 1994, 41, 233-271.

(5) Wu, L.-M.; Wu, X.-T.; Chen, L. Structural overview and structure-property relationships of iodoplumbate and iodobismuthate. Coord. Chem. Rev. 2009, 253 (23), 2787-2804.

(6) Dehnhardt, N.; Luy, J.-N.; Szabo, M.; Wende, M.; Tonner, R.; Heine, J. Synthesis of a two-dimensional organic-inorganic bismuth iodide metalate through in situ formation of iminium cations. Chem. Commun. 2019, 55 (98), 14725-14728.

(7) Li, M.-Q.; Hu, Y.-Q.; Bi, L.-Y.; Zhang, H.-L.; Wang, Y.; Zheng, Y.-Z. Structure Tunable Organic-Inorganic Bismuth Halides for an Enhanced Two-Dimensional Lead-Free Light-Harvesting Material. Chem. Mater. 2017, 29 (13), 5463-5467.

(8) Mitzi, D. B. Organic-Inorganic Perovskites Containing Trivalent Metal Halide Layers: The Templating Influence of the Organic Cation Layer. Inorg. Chem. 2000, 39 (26), 6107-6113.

(9) Lehner, A. J.; Fabini, D. H.; Evans, H. A.; Hebert, C. A.; Smock, S. R.; Hu, J.; Wang, H. B.; Zwanziger, J. W.; Chabinyc, M. L.; Seshadri, R. Crystal and Electronic Structures of Complex Bismuth Iodides $\mathrm{A}_{3} \mathrm{Bi}_{3} \mathrm{I}_{9}(\mathrm{~A}=\mathrm{K}, \mathrm{Rb}, \mathrm{Cs})$ Related to Perovskite: Aiding the Rational Design of Photovoltaics. Chem. Mater. 2015, 27 (20), 71377148.

(10) Mercier, N.; Louvain, N.; Bi, W. H. Structural diversity and retro-crystal engineering analysis of iodometalate hybrids. CrystEngComm 2009, 11 (5), 720-734.

(11) Heine, J.; Wehner, T.; Bertermann, R.; Steffen, A.; MüllerBuschbaum, K. ${ }_{\infty}^{2}\left[\mathrm{Bi}_{2} \mathrm{Cl}_{6}(\mathrm{pyz})_{4}\right]$ : A 2D-Pyrazine Coordination Polymer As Soft Host Lattice for the Luminescence of the Lanthanide Ions $\mathrm{Sm} 3+, \mathrm{Eu}^{3+}, \mathrm{Tb}^{3+}$, and $\mathrm{Dy}^{3+}$. Inorg. Chem. 2014, 53 (14), 71977203.

(12) Heine, J. A step closer to the binary: the ${ }^{1}{ }_{\infty}\left[\mathrm{Bi}_{6} \mathrm{I}_{2} 0\right]^{2-}$ anion. Dalton Trans. 2015, 44 (21), 10069-10077.

(13) Wagner, B.; Dehnhardt, N.; Schmid, M.; Klein, B. P.; Ruppenthal, L.; Müller, P.; Zugermeier, M.; Gottfried, J. M.; Lippert, S.; Halbich, M. U.; Rahimi-Iman, A.; Heine, J. Color Change Effect in an Organic-Inorganic Hybrid Material Based on a Porphyrin Diacid. J. Phys. Chem. C 2016, 120 (49), 28363-28373.

(14) Heidary, N.; Beyer, A.; Volz, K.; Heine, J. Towards the liquid phase exfoliation of bismuth iodide. Dalton Trans. 2017, 46 (26), 8359-8362.

(15) Dehnhardt, N.; Borkowski, H.; Schepp, J.; Tonner, R.; Heine, J. Ternary Iodido Bismuthates and the Special Role of Copper. Inorg. Chem. 2018, 57 (2), 633-640.

(16) Sorg, J. R.; Wehner, T.; Matthes, P. R.; Sure, R.; Grimme, S.; Heine, J.; Müller-Buschbaum, K. Bismuth as a versatile cation for luminescence in coordination polymers from $\mathrm{BiX}_{3} / 4,4$ '-bipy: understanding of photophysics by quantum chemical calculations and structural parallels to lanthanides. Dalton Trans. 2018, 47 (23), 7669-7681.

(17) Dehnhardt, N.; Klement, P.; Chatterjee, S.; Heine, J. Divergent Optical Properties in an Isomorphous Family of Multinary lodido Pentelates. Inorg. Chem. 2019, 58 (16), 10983-10990.

(18) Dehnhardt, N.; Paneth, H.; Hecht, N.; Heine, J. Multinary Halogenido Bismuthates beyond the Double Perovskite Motif. Inorg. Chem. 2020, 59 (6), 3394-3405.

(19) Alcock, N. W.; Ravindran, M.; Willey, G. R. Crown ether complexes of Bi. Synthesis and crystal and molecular structures of
$\mathrm{BiCl}_{3} \cdot 12$-crown-4 and $2 \mathrm{BiCl}_{3} \cdot 18$-crown-6. J. Chem. Soc., Chem. Commun. 1989, No. 15, 1063-1065.

(20) Krautscheid, H. $\left.\mathrm{Bzl}_{4} \mathrm{P}_{2}\right)\left[\mathrm{Bi}_{2} \mathrm{I}_{8}\right]$ - an iodobismuthate with pentacoordinated $\mathrm{Bi}^{3+}$ ions. Z. Anorg. Allg. Chem. 1999, 625 (2), 192-194.

(21) Liu, B.; Xu, L.; Guo, G.-C.; Huang, J.-S. Three inorganicorganic hybrids of bismuth(III) iodide complexes containing substituted 1,2,4-triazole organic components with charaterizations of diffuse reflectance spectra. J. Solid State Chem. 2006, 179 (6), $1611-1617$.

(22) Monakhov, K. Y.; Zessin, T.; Linti, G. Molecular Assemblies Based on $\mathrm{Cp}^{*} \mathrm{BiX}_{2}$ Units $(\mathrm{X}=\mathrm{Cl}, \mathrm{Br}, \mathrm{I})$ : An Experimental and Computational Study. Organometallics 2011, 30 (10), 2844-2854.

(23) James, S. C.; Norman, N. C.; Orpen, A. G.; Quayle, M. J. Tetrahydrofuran Adducts of a Chlorobismuthate(III) Anion and Antimony Triiodide. Acta Crystallogr., Sect. C: Cryst. Struct. Commun. 1997, 53 (8), 1024-1027.

(24) Breunig, H. J.; Denker, M.; Schulz, R. E.; Lork, E. Synthesen und Kristallstrukturanalysen von $\left[\mathrm{SbI}_{3}\left(\mathrm{SbMe}_{3}\right)(\mathrm{THF})\right]_{2}$ und $[\mathrm{Li}-$ $\left.(\mathrm{THF})_{4}\right]_{2}\left[\mathrm{Bi}_{2} \mathrm{Cl}_{8}(\mathrm{THF})_{2}\right]$. Z. Anorg. Allg. Chem. 1998, 624 (1), 8184.

(25) Groer, T.; Scheer, M. Transition-metal-substituted dichlorobismuthanes as starting materials for novel bismuth - transitionmetal clusters. Organometallics 2000, 19 (18), 3683-3691.

(26) Sharutin, V. V.; Sharutina, O. K.; Khisamov, R. M.; Senchurin, V. S. Bismuth complexes $\left[\mathrm{p}-\mathrm{Tol}_{4} \mathrm{P}\right]^{2+}\left[\mathrm{Bi}_{2} \mathrm{I}_{8}(\mathrm{THF})_{2}\right]^{2-}, \quad[\mathrm{p}-$ $\left.\mathrm{Tol}_{4} \mathrm{Sb}\right]^{2+}\left[\mathrm{Bi}_{2} \mathrm{I}_{8}(\mathrm{THF})_{2}\right]^{2-}, \quad\left[\mathrm{p}-\mathrm{Tol}_{4} \mathrm{P}\right]^{2+}\left[\mathrm{Bi}_{2} \mathrm{I}_{8}(\mathrm{DMSO})_{2}\right]^{2-}$, $\left[\mathrm{Bu}_{4} \mathrm{P}\right]^{\mathrm{n}+}\left[\left(\mathrm{Bi}_{2} \mathrm{I}_{7}\right)_{\mathrm{n}}\right]^{\mathrm{n}-},\left[\mathrm{p}-\mathrm{Tol}_{4} \mathrm{P}\right]^{\mathrm{n}+}\left[\left(\mathrm{Bi}_{2} \mathrm{I}_{7}\right)_{\mathrm{n}}\right]^{\mathrm{n}-}$, and $[\mathrm{p}-$ $\left.\mathrm{Tol}_{4} \mathrm{Sb}\right]^{\mathrm{n}+}\left[\left(\mathrm{Bi}_{2} \mathrm{I}_{7}\right)_{\mathrm{n}}\right]^{\mathrm{n}-}$ : Synthesis and structure. Russ. J. Inorg. Chem. 2017, 62 (6), 766-776.

(27) Yu, Y.-H.; Qian, K.; Ye, Y.-H. Synthesis, structure and properties of two H-bonded supramolecular compounds based on 18crown-6 macrocycle. J. Mol. Struct. 2012, 1021, 1-6.

(28) Sharutin, V. V.; Egorova, I. V.; Klepikov, N. N.; Boyarkina, E. A.; Sharutina, O. K. Bismuth compounds $\left[\mathrm{Ph}_{3} \mathrm{BuP}\right]^{+} \mathrm{I}^{-}$, $\left[\mathrm{Ph}_{3} \mathrm{BuP}\right]^{2+}\left[\mathrm{Bi}_{2} \mathrm{I}_{8} \cdot 2 \mathrm{Me}_{2} \mathrm{C}=\mathrm{O}\right]^{2-}$, and $\left[\mathrm{Ph}_{3} \mathrm{BuP}\right]^{2+}\left[\mathrm{Bi}_{2} \mathrm{I}_{8} \cdot 2 \mathrm{Me}_{2} \mathrm{~S}=\right.$ $\mathrm{O}]^{2-}$ : Syntheses and crystal structures. Russ. J. Coord. Chem. 2009, 35 (3), 186-190.

(29) Sharutin, V. V.; Egorova, I. V.; Klepikov, N. N.; Boyarkina, E. A.; Sharutina, O. K. Synthesis and structure of bismuth complexes $\left[\mathrm{Ph}_{3}(\mathrm{n}-\mathrm{Pr}) \mathrm{P}\right]^{2+}\left[\mathrm{Bi}_{2} \mathrm{I}_{8} \cdot 2 \mathrm{Me}_{2} \mathrm{~S}=\mathrm{O}\right]^{2-},\left[\mathrm{Ph}_{3}(\text { iso- } \mathrm{Bu}) \mathrm{P}\right]^{2+}\left[\mathrm{Bi}_{2} \mathrm{I}_{8} \cdot 2 \mathrm{Me}_{2} \mathrm{~S}=\right.$ $\mathrm{O}]^{2-},\left[\mathrm{Ph}_{3}(\mathrm{n}-\mathrm{Bu}) \mathrm{P}\right]^{2+}\left[\mathrm{Bi}_{2} \mathrm{I}_{8} \cdot 2 \mathrm{Me}_{2} \mathrm{~S}=\mathrm{O}\right]^{2-}$, and $\left[\mathrm{Ph}_{3}(\mathrm{n}-\mathrm{Am})-\right.$ $\mathrm{P}]^{2+}\left[\mathrm{Bi}_{2} \mathrm{I}_{8} \cdot 2 \mathrm{Me}_{2} \mathrm{~S}=\mathrm{O}\right]^{2-}$. Russ. J. Inorg. Chem. 2009, 54 (2), 239-247.

(30) Sharutin, V. V.; Senchurin, V. S.; Sharutina, O. K.; Kunkurdonova, B. B.; Platonova, T. P. Synthesis and structure of bismuth complex $\left[\mathrm{n}-\mathrm{Bu}_{4} \mathrm{~N}\right]^{2+}\left[\mathrm{Bi}_{2} \mathrm{I}_{8} \cdot 2 \mathrm{Me}_{2} \mathrm{~S}=\mathrm{O}\right]^{2-}$. Russ. J. Inorg. Chem. 2011, 56 (8), 1272.

(31) Sharutin, V. V.; Senchurin, V. S.; Sharutina, O. K.; Davydova, O. A. Synthesis and structure of bismuth complexes $\left[\mathrm{Ph}_{4} \mathrm{P}\right]_{4}\left[\mathrm{Bi}_{8} \mathrm{I}_{28}\right]$, $\left[\mathrm{Ph}_{4} \mathrm{P}\right]_{2}\left[\mathrm{Bi}_{2} \mathrm{I}_{8} \cdot 2 \mathrm{Me}_{2} \mathrm{~S}=\mathrm{O}\right] \cdot 2 \mathrm{Me}_{2} \mathrm{~S}=\mathrm{O},\left[\left(\mathrm{Me}_{2} \mathrm{~S}=\mathrm{O}\right)_{8} \mathrm{Bi}\right]\left[\mathrm{Bi}_{2} \mathrm{I}_{9}\right]$. Russ. J. Gen. Chem. 2012, 82 (2), 194-198.

(32) Shestimerova, T. A.; Golubev, N. A.; Mironov, A. V.; Bykov, M. A.; Shevelkov, A. V. Synthesis, structure, and properties of Schiff base iodobismuthate and its alteration in DMSO solution. Russ. Chem. Bull. 2018, 67 (7), 1212-1219.

(33) Ahmed, I. A.; Blachnik, R.; Reuter, H. Synthesis and Thermal Behaviour of Compounds in the System $[\mathrm{Ph} 4 \mathrm{P}] \mathrm{Cl} / \mathrm{BiCl} 3$ and the Crystal Structures of $[\mathrm{Ph} 4 \mathrm{P}] 3[\mathrm{Bi} 2 \mathrm{Cl} 9] \cdot 2 \mathrm{CH} 2 \mathrm{Cl} 2$ and $[\mathrm{Ph} 4 \mathrm{P}] 2-$ [Bi2Cl8] $2 \mathrm{CH} 3 \mathrm{COCH} 3$. Z. Anorg. Allg. Chem. 2001, 627 (9), 2057-2062.

(34) Möbs, J.; Heine, J. 11/15/17 Complexes as Molecular Models for Metal Halide Double Perovskite Materials. Inorg. Chem. 2019, 58 (9), 6175-6183.

(35) Charmant, J. P. H.; Norman, N. C.; Orpen, A. G.; Starbuck, J. 4,4 '-bipyridyl adduct of an iodobismuthate anion linked by a 4,4 '-bipyridinium cation. Acta Crystallogr., Sect. E: Struct. Rep. Online 2003, 59, m1000-m1001. 
(36) Soltanzadeh, N.; Morsali, A. Metal-organic supramolecular assemblies generated from bismuth(III) bromide and polyimine ligands. Polyhedron 2009, 28 (4), 703-710.

(37) Chen, Y.; Yang, Z.; Wu, X.-Y.; Ni, C.-Y.; Ren, Z.-G.; Wang, H.F.; Lang, J.-P. Iodobismuthates with $\mathrm{N}$-alkyl- or $\mathrm{N}, \mathrm{N}^{\prime}$-dialkyl-4,4'bipyridinium: syntheses, structures and dielectric properties. Phys. Chem. Chem. Phys. 2011, 13 (13), 5659-5667.

(38) Toma, O.; Mercier, N.; Allain, M.; Botta, C. Protonated Noxide-4,4'-bipyridine: from luminescent $\mathrm{Bi}^{\mathrm{III}}$ complexes to hybrids based on H-bonded dimers or H-bonded open 2D square supramolecular networks. CrystEngComm 2013, 15 (42), 8565-8571.

(39) Yan, X.-W.; Haji-Hasani, E.; Morsali, A. Syntheses and structural characterization of two new nanostructured $\mathrm{Bi}$ (III) supramolecular polymers via sonochemical method. Ultrason. Sonochem. 2016, 31, 129-134.

(40) Kelly, A. W.; Wheaton, A. M.; Nicholas, A. D.; Barnes, F. H.; Patterson, H. H.; Pike, R. D. Iodobismuthate(III) and Iodobismuthate(III)/Iodocuprate(I) Complexes with Organic Ligands. Eur. J. Inorg. Chem. 2017, 4990-5000.

(41) Usoltsev, A. N.; Adonin, S. A.; Abramov, P. A.; Korolkov, I. V.; Yushina, I. V.; Antonova, O. V.; Sokolov, M. N.; Fedin, V. P. Polymeric hybrid iodoplumbates and iodobismuthates containing mono- and bisalkylated derivatives of 1,2-bis(4-pyridyl)ethylene: Structural and optical features. Inorg. Chim. Acta 2017, 462, 323-328.

(42) Ounally, C.; Essid, M.; Bruno, G.; Abid, S.; Faggio, G.; Aloui, Z. Synthesis, crystal structure, vibrational and optical properties of a new $\mathrm{Bi}(\mathrm{III})$ halide complex: $\left(\mathrm{C}_{9} \mathrm{H}_{13} \mathrm{~N}_{2} \mathrm{O}_{2}\right)_{2} \mathrm{Bi}_{2} \mathrm{Cl}_{8}$. J. Mol. Struct. 2019, $1183,52-59$.

(43) Gong, H.-Y.; Zhang, X.-H.; Wang, D.-X.; Ma, H.-W.; Zheng, Q.-Y.; Wang, M.-X. Methylazacalixpyridines: Remarkable Bridging Nitrogen-Tuned Conformations and Cavities with Unique Recognition Properties. Chem. - Eur. J. 2006, 12 (36), 9262-9275.

(44) Lv, L. P.; He, L. J.; Li, W. W.; Yu, W. B.; Hu, X. C. Bis(5amino-4-aminocarbonyl-1H-imidazol-3-ium) (5-amino-4-aminocarbonyl-1H-imidazol-3-ium-kappaO)-di-mu-chlorido-heptachloridodibismuth(III) monohydrate. Acta Crystallogr., Sect. E: Struct. Rep. Online 2008, 64, m643-m644.

(45) Clegg, W.; Norman, N. C.; Pickett, N. L. Synthesis and structure of $\left[\mathrm{SMe}_{3}\right]_{2}\left[\mathrm{Bi}_{2} \mathrm{I}_{8}\left(\mathrm{SMe}_{2}\right)_{2}\right]$ : a dimethylsulphide complex of bismuth(III). Polyhedron 1993, 12 (10), 1251-1252.

(46) Chitnis, S. S.; Burford, N.; Decken, A.; Ferguson, M. J. Coordination Complexes of Bismuth Triflates with Tetrahydrofuran and Diphosphine Ligands. Inorg. Chem. 2013, 52 (12), 7242-7248.

(47) Adcock, A. K.; Batrice, R. J.; Bertke, J. A.; Knope, K. E. Structural Diversity of Bismuth(III) Thiophenemonocarboxylates Isolated from Aqueous Solutions. Eur. J. Inorg. Chem. 2017, 14351445.

(48) Charmant, J. P. H.; Jahan, A. H. M. M.; Norman, N. C.; Orpen, A. G. The preparation and structural characterisation of thiolato anions of bismuth(III). Inorg. Chim. Acta 2005, 358 (5), 1358-1364.

(49) Briand, G. G.; Burford, N.; Stanley Cameron, T. Ammoniumthiolatobismuth halides: a new thiolate bonding environment for BiIII as an alternative to metathesis and chelation. Chem. Commun. 1997, 24, 2365-2366.

(50) Aprile, A.; Corbo, R.; Vin Tan, K.; Wilson, D. J. D.; Dutton, J. L. The first bismuth-NHC complexes. Dalton Trans. 2014, 43 (2), 764-768.

(51) Michaudet, L.; Fasseur, D.; Guilard, R.; Ou, Z.; Kadish, K. M.; Dahaoui, S.; Lecomte, C. Synthesis, characterization and electrochemistry of bismuth porphyrins. X-ray crystal structure of (OEP)$\mathrm{Bi}\left(\mathrm{SO}_{3} \mathrm{CF}_{3}\right)$. J. Porphyrins Phthalocyanines 2000, 04 (3), 261-270.

(52) Wang, G. C.; Freeman, L. A.; Dickie, D. A.; Mokrai, R.; Benkő, Z.; Gilliard, R. J. Highly Reactive Cyclic(alkyl)(amino) Carbene- and N-Heterocyclic Carbene-Bismuth(III) Complexes: Synthesis, Structure, and Computations. Inorg. Chem. 2018, 57 (18), 11687-11695.

(53) Waters, J. B.; Chen, Q.; Everitt, T. A.; Goicoechea, J. M. NHeterocyclic carbene adducts of the heavier group 15 tribromides. Normal to abnormal isomerism and bromide ion abstraction. Dalton Trans. 2017, 46, 12053-12066.
(54) Hupf, E.; Lork, E.; Mebs, S.; Checinska, L.; Beckmann, J. Probing Donor-Acceptor Interactions in peri-Substituted Diphenylphosphinoacenaphthyl-Element Dichlorides of Group 13 and 15 Elements. Organometallics 2014, 33 (24), 7247-7259.

(55) Nejman, P. S.; Curzon, T. E.; Bühl, M.; McKay, D.; Woollins, J. D.; Ashbrook, S. E.; Cordes, D. B.; Slawin, A. M. Z.; Kilian, P. Phosphorus-Bismuth Peri-Substituted Acenaphthenes: A Synthetic, Structural, and Computational Study. Inorg. Chem. 2020, 59 (8), $5616-5625$.

(56) Mokrai, R.; Barrett, J.; Apperley, D. C.; Batsanov, A. S.; Benkő, Z.; Heift, D. Weak Pnictogen Bond with Bismuth: Experimental Evidence Based on Bi-P Through-Space Coupling. Chem. - Eur. J. 2019, 25 (16), 4017-4024.

(57) Tolstikova, L. L.; Bel'skikh, A. V.; Shainyan, B. A. Protonation and alkylation of organophosphorus compounds with trifluoromethanesulfonic acid derivatives. Russ. J. Gen. Chem. 2011, 81 (3), 474.

(58) Mokrai, R.; Barrett, J.; Apperley, D. C.; Benkő, Z.; Heift, D. Tweaking the Charge Transfer: Bonding Analysis of Bismuth(III) Complexes with a Flexidentate Phosphane Ligand. Inorg. Chem. 2020, 59 (13), 8916-8924.

(59) Bardají, M.; Crespo, O.; Laguna, A.; Fischer, A. K. Structural characterization of silver $(\mathrm{I})$ complexes $\left[\mathrm{Ag}\left(\mathrm{O}_{3} \mathrm{SCF}_{3}\right)(\mathrm{L})\right]\left(\mathrm{L}=\mathrm{PPh}_{3}\right.$, $\left.\mathrm{PPh}_{2} \mathrm{Me}, \mathrm{SC}_{4} \mathrm{H}_{8}\right)$ and $[\mathrm{AgLn}]\left(\mathrm{CF}_{3} \mathrm{SO}_{3}\right)(\mathrm{n}=2-4),\left(\mathrm{L}=\mathrm{PPh}_{3}\right.$, $\mathrm{PPh}_{2} \mathrm{Me}$ ). Inorg. Chim. Acta 2000, 304 (1), 7-16.

(60) Krachko, T.; Lyaskovskyy, V.; Lutz, M.; Lammertsma, K.; Slootweg, J. C. Brønsted Acid Promoted Reduction of Tertiary Phosphine Oxides. Z. Anorg. Allg. Chem. 2017, 643 (14), 916-921.

(61) Wheeler, R. A.; Kumar, P. N. V. P. Stereochemically Active or Inactive Lone Pair Electrons in Some 6-Coordinate, Group-15 Halides. J. Am. Chem. Soc. 1992, 114 (12), 4776-4784.

(62) Silvestru, C.; Breunig, H. J.; Althaus, H. Structural chemistry of bismuth compounds. I. Organobismuth derivatives. Chem. Rev. 1999, 99 (11), 3277-3327.

(63) Clegg, W.; Elsegood, M. R. J.; Norman, N. C.; Pickett, N. L. Anionic Phosphine Complexes of Antimony(III) and Bismuth(III) Halogenoanions. J. Chem. Soc., Dalton Trans. 1994, No. 12, 17531757.

(64) Imran, M.; Neumann, B.; Stammler, H. G.; Monkowius, U.; Ertl, M.; Mitzel, N. W. The versatile behaviour of a novel Janus scorpionate ligand towards sodium, potassium and bismuth(III) ions. Dalton Trans. 2013, 42 (44), 15785-15795.

(65) Clegg, W.; Errington, R. J.; Fisher, G. A.; Green, M. E.; Hockless, D. C. R.; Norman, N. C. A Phosphine Complex of Bismuth(III) - X-Ray Crystal-Structure of $\left[\mathrm{PMe}_{3} \mathrm{H}\right]\left[\mathrm{Bi}_{2} \mathrm{Br}_{7}\left(\mathrm{PMe}_{3}\right)_{2}\right]$. Chem. Ber. 1991, 124 (11), 2457-2459.

(66) Clegg, W.; Errington, R. J.; Flynn, R. J.; Green, M. E.; Hockless, D. C. R.; Norman, N. C.; Gibson, V. C.; Tavakkoli, K. Edge-shared, bioctahedral, bismuth phosphine complexes. J. Chem. Soc., Dalton Trans. 1992, No. 10, 1753-1754.

(67) Brown, I. D. VALENCE: A program for calculating bond valences. J. Appl. Crystallogr. 1996, 29, 479-480.

(68) Brese, N. E.; O’Keeffe, M. Bond-Valence Parameters for Solids. Acta Crystallogr., Sect. B: Struct. Sci. 1991, 47, 192-197.

(69) Mantina, M.; Chamberlin, A. C.; Valero, R.; Cramer, C. J.; Truhlar, D. G. Consistent van der Waals Radii for the Whole Main Group. J. Phys. Chem. A 2009, 113 (19), 5806-5812.

(70) De Groot, B.; Giesbrecht, G. R.; Loeb, S. J.; Shimizu, G. K. H. Copper(I) and silver(I) complexes of the crown thioether ligand 2,5,8-trithia[9]-o-benzenophane (TT[9]OB). Structures of $[\mathrm{Cu}-$ $\left.\left(\mathrm{PPh}_{2} \mathrm{Me}\right)(\mathrm{TT}[9] \mathrm{OB})\right]\left[\mathrm{ClO}_{4}\right]$ and $\left[\mathrm{Ag}\left(\mathrm{PPh}_{3}\right)(\mathrm{TT}[9] \mathrm{OB})\right]\left[\mathrm{ClO}_{4}\right]$. Inorg. Chem. 1991, 30 (2), 177-182.

(71) Weis, P.; Hettich, C.; Kratzert, D.; Krossing, I. Homoleptic Silver Complexes of the Cages $\mathrm{P}_{4} \mathrm{Se}_{3}$ and $\mathrm{As}_{4} \mathrm{~S}_{3}$. Eur. J. Inorg. Chem. 2019, 1657-1668.

(72) Batsanov, S. S. Van-Der-Waals Radii of Elements from the Data of Structural Inorganic-Chemistry. Russ. Chem. Bull. 1995, 44 (1), $18-23$.

(73) Cremer, D.; Kraka, E. Chemical-Bonds without Bonding Electron-Density - Does the Difference Electron-Density Analysis 
Suffice for a Description of the Chemical-Bond. Angew. Chem., Int. Ed. Engl. 1984, 23 (8), 627-628.

(74) Cremer, D.; Kraka, E. A Description of the Chemical-Bond in Terms of Local Properties of Electron-Density and Energy. Croat. Chem. Acta 1984, 57 (6), 1259-1281.

(75) Halldin Stenlid, J.; Johansson, A. J.; Brinck, T. $\sigma$-Holes and $\sigma$ lumps direct the Lewis basic and acidic interactions of noble metal nanoparticles: introducing regium bonds. Phys. Chem. Chem. Phys. 2018, 20 (4), 2676-2692.

(76) Stenlid, J. H.; Brinck, T. Extending the $\sigma$-Hole Concept to Metals: An Electrostatic Interpretation of the Effects of Nanostructure in Gold and Platinum Catalysis. J. Am. Chem. Soc. 2017, 139 (32), 11012-11015.

(77) Legon, A. C.; Walker, N. R. What's in a name? 'Coinage-metal' non-covalent bonds and their definition. Phys. Chem. Chem. Phys. 2018, 20 (29), 19332-19338.

(78) Bauzá, A.; Alkorta, I.; Elguero, J.; Mooibroek, T. J.; Frontera, A. Spodium Bonds: Noncovalent Interactions Involving Group 12 Elements. Angew. Chem. 2020, DOI: 10.1002/ange.202007814.

(79) Lucas, C. R.; Liu, S.; Newlands, M. J.; Charland, J.-P.; Gabe, E. J. Thiophenophane metal complexes. III. Preparation, X-ray structure, and properties of 2,5,7,10-tetrathia[12] $(2,5)$ thiophenophane, $\mathrm{L}$, and $\left[\mathrm{Ag}_{2} \mathrm{~L}_{2}\right]^{2+}$, its dinuclear silver complex cation. Can. J. Chem. 1990, 68 (4), 644-649.

(80) Blower, P. J.; Clarkson, J. A.; Rawle, S. C.; Hartman, J. R.; Wolf, R. E.; Yagbasan, R.; Bott, S. G.; Cooper, S. R. Crown thioether chemistry. The silver(I) complexes of trithia-9-crown-3, trithia-12crown-3, and hexathia-18-crown-6. Inorg. Chem. 1989, 28 (21), 4040-4046.

(81) Akabori, S.; Sato, S.; Sato, M.; Takanohashi, Y. Dinuclear Complexes of Tetrathia[10]metallocenophanes with Silver(I) Ion: Slightly Distorted Square-Pyramidal Coordination of Ag(I) Ion. Bull. Chem. Soc. Jpn. 1989, 62 (5), 1582-1586.

(82) Carlucci, L.; Ciani, G.; Proserpio, D. M.; Sironi, A. Novel Networks of Unusually Coordinated Silver(I) Cations: The WaferLike Structure of $\left[\mathrm{Ag}(\mathrm{pyz})_{2}\right]\left[\mathrm{Ag}_{2}(\mathrm{pyz})_{5}\right]\left(\mathrm{PF}_{6}\right)_{3} \cdot 2 \mathrm{G}$ and the Simple Cubic Frame of $\left[\mathrm{Ag}(\mathrm{pyz})_{3}\right]\left(\mathrm{SbF}_{6}\right)$. Angew. Chem., Int. Ed. Engl. 1995, 34 (17), 1895-1898.

(83) Hirsch, K. A.; Wilson, S. R.; Moore, J. S. Coordination Networks of 3,3'-Dicyanodiphenylacetylene and Silver(I) Salts: Structural Diversity through Changes in Ligand Conformation and Counterion. Inorg. Chem. 1997, 36 (14), 2960-2968.

(84) Tsuchiya, T.; Shimizu, T.; Hirabayashi, K.; Kamigata, N. Silver Complexes with Unsaturated Thiacrown Ethers: Inclusion Behavior of Conformationally Restricted Macrocycles. J. Org. Chem. 2002, 67 (19), 6632-6637.

(85) Kokunov, Y. V.; Gorbunova, Y. E.; Kovalev, V. V. Ribbon structure of the coordination polymer of silver trifluoroacetate with 2pyrimidinecarboxamide. Russ. J. Inorg. Chem. 2009, 54 (12), 1909.

(86) Fernandez-Anca, D.; Garcia-Seijo, M. I.; Garcia-Fernandez, M. E. Tripodal polyphosphine ligands as inductors of chelate ringopening processes in mononuclear palladium(II) and platinum(II) compounds. The X-ray crystal structure of two derivatives containing dangling phosphorus. Dalton Trans. 2010, 39 (9), 2327-2336.

(87) Cvengroš, J.; Maennel, E.; Santschi, N. Synthesis and characterization of novel S,N and Se,N homodimetallic $\mathrm{Ag}(\mathrm{I})$ complexes. Dalton Trans. 2012, 41 (24), 7415-7422.

(88) Bolotin, D. S.; Soldatova, N. S.; Demakova, M. Y.; Novikov, A. S.; Ivanov, D. M.; Aliyarova, I. S.; Sapegin, A.; Krasavin, M. Pentacoordinated silver(I) complex featuring 8-phenylquinoline ligands: Interplay of coordination bonds, semicoordination, and stacking interactions. Inorg. Chim. Acta 2020, 504, 119453.

(89) For structural parameter calculations see: http://kchn.pg.gda. $\mathrm{pl} /$ geom/.

(90) Addison, A. W.; Rao, T. N.; Reedijk, J.; van Rijn, J.; Verschoor, G. C. Synthesis, structure, and spectroscopic properties of copper(II) compounds containing nitrogen-sulphur donor ligands; the crystal and molecular structure of aqua[1,7-bis $(\mathrm{N}$-methylbenzimidazol-2' -
yl)-2,6-dithiaheptane]copper(II) perchlorate. J. Chem. Soc., Dalton Trans. 1984, No. 7, 1349-1356.

(91) Haav, K.; Saame, J.; Kutt, A.; Leito, I. Basicity of Phosphanes and Diphosphanes in Acetonitrile. Eur. J. Org. Chem. 2012, 21672172.

(92) Abdur-Rashid, K.; Fong, T. P.; Greaves, B.; Gusev, D. G.; Hinman, J. G.; Landau, S. E.; Lough, A. J.; Morris, R. H. An Acidity Scale for Phosphorus-Containing Compounds Including Metal Hydrides and Dihydrogen Complexes in THF: Toward the Unification of Acidity Scales. J. Am. Chem. Soc. 2000, 122 (38), 9155-9171.

(93) van den Akker, M.; Jellinek, F. Triphenylphosphonium and triethylphosphonium halides. Recl. Trav. Chim. Pays-Bas 1967, 86 (3), 275-288.

(94) Sheldon, J. C.; Tyree, S. Y. Triphenylphosphonium Salts. J. Am. Chem. Soc. 1958, 80 (9), 2117-2120.

(95) Herbowski, A.; Lis, T. Synthesis of 1,2-ethanediylbis(diphenylphosphonium)-PH, $\mathrm{P}^{\prime} \mathrm{H}^{\prime}$ hexachloromolybdate(III) I and nonachlorodimolybdate(III) II. The crystal structure of $\left(\mathrm{dppeH}_{2}\right)_{3}\left[\mathrm{MoCl}_{6}\right]_{2} \cdot 12 \mathrm{H} 2 \mathrm{O}$. Polyhedron 1985, 4 (1), 127-131.

(96) Kohle, R.; Kuchen, W.; Peters, W. Phosphoniumsalze mit Hydrogendihalogenidanionen $\mathrm{HCl}_{2}^{-}, \mathrm{HBr}_{2}{ }^{-} \mathrm{HI}_{2}{ }^{-}$oder $\mathrm{HBrCl}^{-} . \mathrm{Z}$. Anorg. Allg. Chem. 1987, 551 (8), 179-190.

(97) Mita, T.; Jacobsen, E. N. Bifunctional Asymmetric Catalysis with Hydrogen Chloride: Enantioselective Ring Opening of Aziridines Catalyzed by a Phosphinothiourea. Synlett 2009, 1680-1684.

(98) Zong, J.; Mague, J. T.; Kraml, C. M.; Pascal, R. A. A Congested in,in-Diphosphine. Org. Lett. 2013, 15 (9), 2179-2181.

(99) Chitnis, S. S.; Robertson, A. P. M.; Burford, N.; Patrick, B. O.; McDonald, R.; Ferguson, M. J. Bipyridine complexes of $\mathrm{E}^{3+}(\mathrm{E}=\mathrm{P}$, $\mathrm{As}, \mathrm{Sb}, \mathrm{Bi})$ : strong Lewis acids, sources of $\mathrm{E}(\mathrm{OTf})_{3}$ and synthons for $\mathrm{E}^{\mathrm{I}}$ and $\mathrm{E}^{\mathrm{V}}$ cations. Chem. Sci. 2015, 6 (11), 6545-6555.

(100) Kannan, R.; Kumar, S.; Andrews, A. P.; Jemmis, E. D.; Venugopal, A. Consequence of Ligand Bite Angle on Bismuth Lewis Acidity. Inorg. Chem. 2017, 56 (16), 9391-9395.

(101) Johnson, J. A.; Venugopal, A. Probing the Lewis acidity of heavier pnictogen trichlorides. J. Chem. Sci. 2019, 131 (12), 114.

(102) Ramler, J.; Hofmann, K.; Lichtenberg, C. Neutral and Cationic Bismuth Compounds: Structure, Heteroaromaticity, and Lewis Acidity of Bismepines. Inorg. Chem. 2020, 59 (6), 3367-3376.

(103) Ramler, J.; Lichtenberg, C. Molecular Bismuth Cations: Assessment of Soft Lewis Acidity. Chem. - Eur. J. 2020, 26, 1025010258 .

(104) Marczenko, K. M.; Jee, S.; Chitnis, S. S. High Lewis Acidity at Planar, Trivalent, and Neutral Bismuth Centers. Organometallics 2020, DOI: 10.1021/acs.organomet.0c00378. 